\title{
A Simple Theoretical Approach of Aqueous Solutions of Salts and Organic Solvents in Paper Chromatography
}

\author{
Jacques P. Viejo (1) \\ Association Française de Normalisation, Université Paris Descartes, 1, rue de Fleurus, 75006 Paris, France \\ Email: viejoj@free.fr
}

How to cite this paper: Viejo, J.P. (2019) A Simple Theoretical Approach of Aqueous Solutions of Salts and Organic Solvents in Paper Chromatography. American Journal of Analytical Chemistry, 10, 255-285. https://doi.org/10.4236/ajac.2019.108020

Received: December 24, 2018

Accepted: August 3, 2019

Published: August 6, 2019

Copyright $\odot 2019$ by author(s) and Scientific Research Publishing Inc. This work is licensed under the Creative Commons Attribution International License (CC BY 4.0).

http://creativecommons.org/licenses/by/4.0/

\begin{abstract}
The purpose of this study is to determine the properties of the solvents responsible of the chromatographic phenomenon. A simple and homogeneous system of ascending chromatography on paper is described, allowing varying only one of the factors constituting it. This method made it possible to determine constants by means of a simple equation. The validity of the method is deduced from the good agreement between its mathematical expression and the experimental values obtained.
\end{abstract}

\section{Keywords}

Paper Chromatography, Aqueous Solvent, Organic Solvent, Theory

\section{Introduction}

The technique named "chromatography" got its credentials early in 1903 by Tswett [1] who's Russian name means "color". It then has exploded since 1940 and has been the subject of many practical publications in the fields of chemistry, physics and biology. The chromatographic phenomenon is based on the simple and general principle of the adsorption/desorption of molecules towards solid surfaces, highlighted by Langmuir in 1918 [2]. In 1931 Kuhn and Lederer [3] rediscovered the separate power of column chromatography. In 1944, Consden, Gordon and Martin [4] replaced the column with a sheet of filter paper, making it possible to reduce the test portion to one thousandth of a milligram. Improvements and evolutions have led the original chromatography technique to flourish in a wide range of specialized developments [5] [6] with simple applications in the separation of sugar and amino acids [7] [8]. Since then, gas chromatography has brought a rigor that has developed many theories on this 
system, rapidly followed by the wide development of liquid/liquid chromatography under pressure. The universality of the adsorption/desorption principle accepts all kinds of complications in order to obtain the best separation of the substances in mixture. This facility paradoxically leads to a complicated interpretation of the phenomenon [9] [10]. We present here a chromatographic numerical description as simple as possible to varying only one component of the system, either in aqueous or organic solvents. The results obtained by this means showed a good agreement between its mathematical expression and experimental values. The general idea of this work is to connect the mathematical expression presented here to the other separative techniques.

\section{Material and Methods}

Four water-soluble anionic dyes in sodium form (Figure 1) were used as controls for their $R f$ variations. Indeed, these dyes chromatographed with pure water are found "crushed" under the solvent front. The addition of salts in increasing amounts allowed to regularly varying their $R f$ from zero to one.<smiles>O=[N+]([O-])c1cc(S(=O)(=O)O[Na])cc2ccc(O)c(N=Nc3ccccc3)c12</smiles>

Orange $\mathbf{G}(M w=452.40)$<smiles>CS(=O)(=O)Oc1ccc(N=Nc2c(O)ccc3cc(S(=O)(=O)O[Na])ccc23)cc1</smiles>

Orange $\mathrm{S}(M w=452.40)$

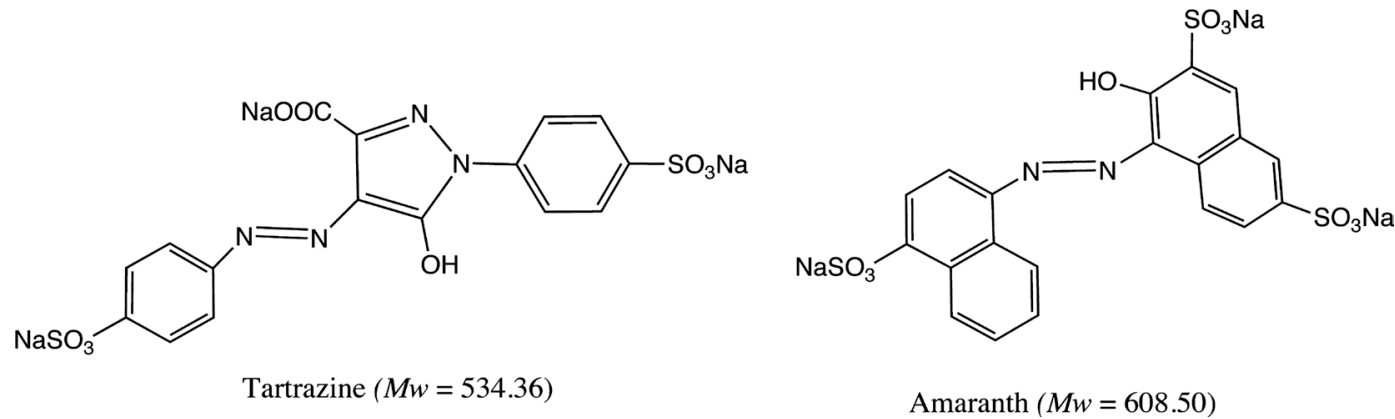

Figure 1. The colored controls in use.

For practical reasons, in order to integrate hydrates and possible solvating water molecules, the salts are dissolved in one liter of solution. The molarity is restored in molality from the anhydrous form of the salts according to:

$$
\text { Molality }=\frac{1000(\% \text { salt })}{M w \text { salt }(100-\% \text { salt })}
$$

The salts in solution act in a static manner according to their molecular volume $M V$, which is more representative of the concept of space occupied by the chromatographic space, than the molecular weight $M w$ of the added salt. The physical properties of the substances are volume properties, whereas the $R f$ s are 
linear parameters. To unify the equations, we use the cubic root of these physical values. The concentrations of these electrolytes are calculated according to:

$$
\sqrt[3]{\frac{N_{1}}{N_{1} M V_{1}+N_{2} M V_{2}}}
$$

$N_{1}$ : Molale concentration of added salt.

$M V_{1}$ : Molecular volume of added salt.

$N_{2} M V_{2}=\frac{1000}{18.015}=55.509$ : molale fraction of $1000 \mathrm{~g}$ of water.

We propose that a salt in aqueous solution at $20^{\circ} \mathrm{C}$ should be in its richest form of water of crystallization $n_{1} \mathrm{H}_{2} \mathrm{O}$ which determines the molecular volume, while the solvation water molecules $n_{x} \mathrm{H}_{2} \mathrm{O}$ increase the concentration salts. In this case, the amount of available free water in which the chromatographic phenomenon develops is calculated according to:

$$
N_{2} M V_{2}=\frac{1000-\left[N_{1}\left(n_{1} \mathrm{OH}+n_{x} \mathrm{OH}\right)\right]}{18.015}<55.509
$$

When the anion is polyvalent and the cations are monovalent $n M^{+}$the equation becomes generalized as follows:

$$
\sqrt[3]{\left[\frac{N_{1}}{\left.\left[\frac{N_{1}}{n M^{+}}\right) M V_{1}+\frac{1000-\left[\left(\frac{N_{1}}{n M^{+}}\right) 18.015 n\right]}{18.015}\right]}\right.}
$$

The concentrations are reduced by the molecular weight of the added salt, resulting in a characteristic curve of each substance chromatographed by means of a homologous series of salts:

$$
\sqrt[3]{\frac{N_{1}}{\frac{N_{1} M V_{1}+N_{2} M V_{2}}{M w_{1}}}}
$$

Equations (1) and (4) will be noted abbreviated in the tables and figures as:

$$
\sqrt[3]{N \cdot M V} \text { and } \sqrt[3]{\frac{N \cdot M V}{M w}}
$$

The choice to record the ratio of the molecular concentration according to the cubic root normalizes the values of $R f(0$ to 1$)$ with respect to concentration and avoids the use of semi-logarithmic representation which often hides some interesting properties. Our personal data are compiled in tables and other numerical data were found in the Handbook of Chemistry and Physics (50 ${ }^{\text {th }}$ Ed. 1969-1970).

We used the ascending chromatography technique on Whatman $\mathrm{N}^{\circ} 2$ paper held in a self-supporting cylinder using stainless steel staples, deposited in the developing liquid, all under a cylindrical glass bell to limit the evaporation of the solvent, especially when it comes to mixtures of organic solvents. The control 
dyes are deposited on a line located $3 \mathrm{~cm}$ from the bottom of the sheet and the $R f$ are measured relatively from this point of departure to the solvent front.

\section{Experimental Results}

The method described above made it possible to calculate specific values and parameters for each homogeneous series of salts, such as:

$-R f_{x}^{0}$ is the point of equilibrium between the adsorption power of the cellulosic support and the eluting power of the saline solution for each dye, in terms of salt concentration.

$-C_{0}^{0}$ is the common endpoint expressed in terms of $R f$ of a homologous series of salts corresponding to the zero salt concentration of the eluent.

- $R f_{0}^{0}=\frac{R f_{x}^{0} / C_{x}^{0}}{\sqrt[3]{M w_{x}}}$ is common for each homologous series of salts. (5)

Allows construct a second common curve for each homogeneous series of salts on the same scale, grouping a homologous series of salts, which lead to the point $R f_{0}^{0}$. This value makes it possible to confirm the $R f_{x}^{0}$ according to:

$$
R f_{0}^{0} \cdot \sqrt[3]{M w_{x}}=R f_{x}^{0}
$$

\subsection{Aqueous Solutions of Electrolytes}

\subsubsection{Halides of Monovalent Salts}

The $R f$ are plotted on the y-axis while the volume dilutions (Equation (1)) as well as their reduction by their molecular weight respective are potted on the $\mathrm{x}$-axis.

The $R f$ of potassium and sodium halides results are grouped in Table 1 and Table 2, with the exception of potassium fluoride. The experimental $R f$ columns aligned under each dye are ranked in ascending order to better reveal the limitations of paper chromatography.

a) Potassium Halides

The experimentally $R f$ Table 1 is reported in Figure 2 according to the concentrations expressed in volumes according to Equations (1) and (4). The rightmost curves represent the evolution of dyes according to the salt used. The left curve represents the reduction in concentrations by the molecular weight of the added salt resulting in a single straight line characteristic of a homologous series of salts.

Table 1. Dyes and potassium halides.

Potassium chloride $\mathrm{KCl}=74.56$

\begin{tabular}{ccccccc}
\hline Molality & $\sqrt[3]{N \cdot M V} \quad \sqrt[2]{\frac{N \cdot M V}{74.56}}$ & Orange G & Orange S & Tartrazine & Amaranth \\
\hline 1.08 & 0.224 & 1.08 & $0.40-0.41$ & $0.10-0.11$ & $0.10-0.12$ & $0.02-0.03$ \\
0.52 & 0.190 & 0.042 & $0.47-0.49$ & $0.14-0.15$ & $0.15-0.18$ & $0.04-0.05$ \\
\hline
\end{tabular}




\section{Continued}

\begin{tabular}{ccccccc}
\hline 0.254 & 0.157 & 0.036 & $0.54-0.55$ & $0.18-0.20$ & $0.23-0.25$ & $0.07-0.08$ \\
0.108 & 0.119 & 0.028 & $0.65-0.66$ & $0.25-0.27$ & $0.31-0.32$ & $0.12-0.13$ \\
0.050 & 0.095 & 0.022 & $0.71-0.72$ & $0.30-0.30$ & $0.41-0.41$ & $0.17-0.18$ \\
0.025 & 0.076 & 0.018 & $0.77-0.78$ & $0.33-0.34$ & $0.46-0.47$ & $0.20-0.21$ \\
0.010 & 0.056 & 0.013 & $0.83-0.88$ & $0.39-0.40$ & $0.51-0.55$ & $0.30-0.36$ \\
d. salt: & 1.984 & $\frac{R f^{\circ}}{C^{\circ}}$ & $\frac{0.38}{0.95}=0.40$ & $\frac{0.28}{0.47}=0.60$ & $\frac{0.25}{0.66}=0.38$ & $\frac{0.20}{0.32}=0.62$ \\
\hline
\end{tabular}

Potassium bromide $\mathrm{Br}=119.01$

\begin{tabular}{|c|c|c|c|c|c|c|}
\hline Molality & $\sqrt[3]{N \cdot M V}$ & $\sqrt[3]{\frac{N \cdot M V}{119}}$ & Orange G & Orange S & Tartrazine & Amaranth \\
\hline 1.13 & 0.221 & 0.045 & $0.47-0.47$ & $0.15-0.16$ & $0.15-0.17$ & $0.03-0.04$ \\
\hline 0.53 & 0.189 & 0.038 & $0.53-0.53$ & $0.18-0.18$ & $0.19-0.20$ & $0.05-0.06$ \\
\hline 0.26 & 0.157 & 0.032 & $0.61-0.62$ & $0.23-0.24$ & $0.26-0.28$ & $0.09-0.09$ \\
\hline 0.10 & 0.119 & 0.024 & $0.65-0.66$ & $0.26-0.27$ & $0.34-0.39$ & $0.12-0.14$ \\
\hline 0.05 & 0.095 & 0.019 & $0.72-0.73$ & $0.32-0.33$ & $0.41-0.45$ & $0.15-0.17$ \\
\hline 0.025 & 0.076 & 0.015 & $0.76-0.79$ & $0.33-0.36$ & $0.47-0.48$ & $0.20-0.23$ \\
\hline 0.010 & 0.056 & 0.011 & $0.89-0.90$ & $0.42-0.42$ & $0.71-0.72$ & $0.26-0.30$ \\
\hline $\begin{array}{c}\text { d. salt: } \\
M V:\end{array}$ & $\begin{array}{c}2.75 \\
43.276\end{array}$ & $\frac{R f^{\circ}}{C^{\circ}}$ & $\frac{0.44}{0.95}=0.46$ & $\frac{0.33}{0.47}=0.70$ & $\frac{0.29}{0.66}=0.44$ & $\frac{0.225}{0.32}=0.70$ \\
\hline \multicolumn{7}{|c|}{ Potassium Iodide KI = 166.01} \\
\hline Molality & $\sqrt[3]{N \cdot M V}$ & $\sqrt[3]{\frac{N \cdot M V}{166}}$ & Orange $\mathrm{G}$ & Orange S & Tartrazine & Amaranth \\
\hline 1.20 & 0.216 & 0.039 & $0.55-0.57$ & $0.21-0.27$ & $0.24-0.30$ & $0.05-0.07$ \\
\hline 0.54 & 0.186 & 0.034 & $0.60-0.64$ & $0.24-0.24$ & $0.30-0.33$ & $0.09-0.09$ \\
\hline 0.26 & 0.155 & 0.028 & $0.67-0.68$ & $0.29-0.29$ & $0.34-0.37$ & $0.13-0.13$ \\
\hline 0.10 & 0.118 & 0.021 & $0.73-0.73$ & $0.32-0.33$ & $0.41-0.42$ & $0.15-0.18$ \\
\hline 0.05 & 0.095 & 0.017 & $0.77-0.77$ & $0.33-0.35$ & $0.47-0.48$ & $0.20-0.22$ \\
\hline 0.025 & 0.076 & 0.014 & $0.79-0.84$ & $0.36-0.38$ & $0.53-0.59$ & $0.29-0.34$ \\
\hline 0.010 & 0.056 & 0.010 & $0.91-0.91$ & $0.46-0.46$ & $0.63-0.64$ & $0.36-0.39$ \\
\hline $\begin{array}{l}\text { d salt: } \\
\text { MV: }\end{array}$ & $\begin{array}{c}3.13 \\
53.038\end{array}$ & $\frac{R f^{\circ}}{C^{\circ}}$ & $\frac{0.52}{0.95}=0.55$ & $\frac{0.38}{0.47}=0.81$ & $\frac{0.34}{0.66}=0.51$ & $\frac{0.255}{0.32}=0.79$ \\
\hline
\end{tabular}



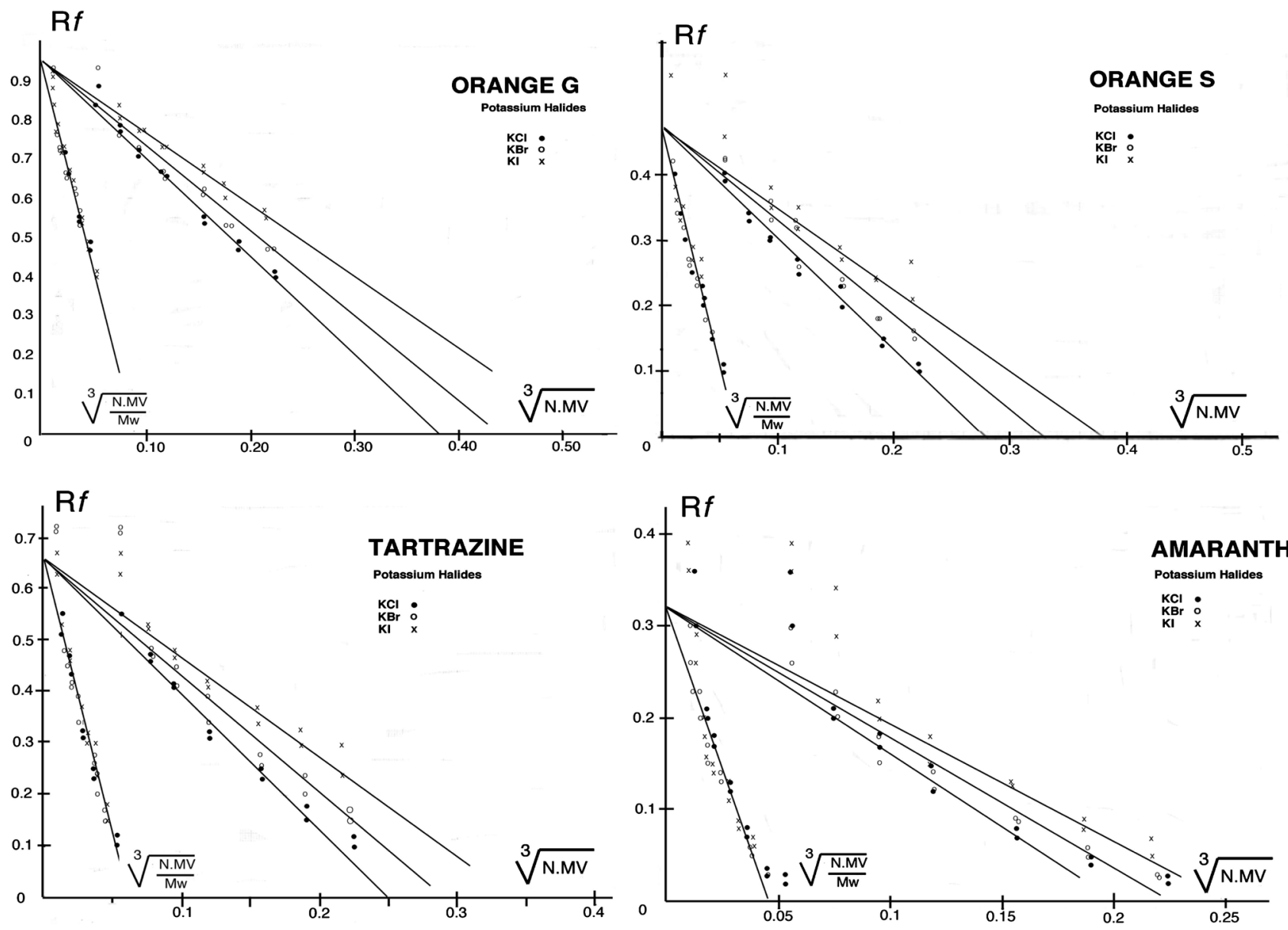

Figure 2. Curves of dyes and potassium halides.

\section{b) Sodium Halides}

The interpretations of these two tables (as well Figure 2 and Figure 3) involve some remarks: the potassium salts are all anhydrous; their interpretation is facilitated compared to the sodium halides hydrated. Each dye has a specifically $R f_{x}^{0}$ depending of the used salt and a common $C_{x}^{0}$ for a homologous series of salts, but in the case of sodium halides, there is a constant offset of 0.09 in term of $R f$ between the $C_{x}^{0}$ of the anhydrous form and that of the hydrated form corresponding to two molecules of water of crystallization and this is valid for all the tested dyes, except for Orange G which seems "blocked" under the solvent front. This value of 0.09 should be added to the experimental $C_{x}^{0}=0.93$ for anhydrous fluoride and chloride on give the theoretical $C_{x}^{0}=1.02$ for bromide and the two sodium iodide hydrates so than their $R f$ s align now on their respective lines. For Orange $G$ to answer Equation (5), it must be admitted that sodium iodide captures four molecules of solvation water, hence a new molecular weight $\mathrm{Mw}=258.15$ (See Table 4). Equation (5) highlights new common properties for each dye chromatographed by a homologous series of alkaline earth halides: 
Table 2. Dyes and sodium halides.

\begin{tabular}{|c|c|c|c|c|c|c|}
\hline \multicolumn{7}{|c|}{ Sodium fluoride $\mathrm{Na} F=41.99$} \\
\hline Molality & $\sqrt[3]{N \cdot M V}$ & $\sqrt[3]{\frac{N \cdot M V}{42}}$ & Orange G & Orange S & Tartrazine & Amaranth \\
\hline 1.04 & 0.243 & 0.070 & $0.41-0.43$ & $0.10-0.11$ & $0.14-0.16$ & $0.04-0.04$ \\
\hline 0.51 & 0.203 & 0.058 & $0.51-0.55$ & $0.16-0.17$ & $0.22-0.23$ & $0.05-0.08$ \\
\hline 0.25 & 0.161 & 0.046 & $0.61-0.64$ & $0.22-0.24$ & $0.30-0.32$ & $0.10-0.11$ \\
\hline 0.10 & 0.120 & 0.034 & $0.68-0.70$ & $0.24-0.27$ & $0.36-0.39$ & $0.14-0.16$ \\
\hline 0.05 & 0.096 & 0.026 & $0.72-0.79$ & $0.30-0.30$ & $0.41-0.45$ & $0.16-0.19$ \\
\hline 0.025 & 0.076 & 0.022 & $0.82-0.83$ & $0.36-0.39$ & $0.50-0.52$ & $0.26-0.26$ \\
\hline 0.010 & 0.056 & 0.016 & $0.84---$ & $0.44---$ & $0.61---$ & $0.33---$ \\
\hline $\begin{array}{l}\text { d. salt: } \\
\text { MV: }\end{array}$ & $\begin{array}{c}2.558 \\
16.415\end{array}$ & $\frac{R f^{0}}{C^{0}}$ & $\frac{0.47}{0.93}=0.50$ & $\frac{0.32}{0.45}=0.71$ & $\frac{0.31}{0.64}=0.48$ & $\frac{0.23}{0.36}=0.64$ \\
\hline
\end{tabular}

\begin{tabular}{|c|c|c|c|c|c|c|}
\hline \multicolumn{7}{|c|}{ Sodium chloride $\mathrm{NaCl}=58.44$} \\
\hline Molality & $\sqrt[3]{N \cdot M V}$ & $\sqrt[3]{\frac{N \cdot M V}{58.44}}$ & Orange G & Orange S & Tartrazine & Amaranth \\
\hline 1.09 & 0.234 & 0.060 & $0.51-0.52$ & $0.16-0.18$ & $0.21-0.22$ & $0.04-0.05$ \\
\hline 0.53 & 0.196 & 0.050 & $0.57-0.60$ & $0.21-0.22$ & $0.28-0.29$ & $0.08-0.10$ \\
\hline 0.26 & 0.160 & 0.041 & $0.64-0.65$ & $0.25-0.26$ & $0.32-0.34$ & $0.12-0.13$ \\
\hline 0.10 & 0.120 & 0.031 & $0.71-0.72$ & $0.30-0.31$ & $0.41-0.42$ & $0.17-0.19$ \\
\hline 0.05 & 0.096 & 0.024 & $0.76-0.78$ & $0.32-0.35$ & $0.46-0.47$ & $0.21-0.23$ \\
\hline 0.025 & 0.076 & 0.019 & $0.80-0.83$ & $0.36-0.37$ & $0.52-0.53$ & $0.23-0.25$ \\
\hline 0.010 & 0.056 & 0.014 & $0.86-0.88$ & $0.42-0.42$ & $0.63-0.64$ & $0.32-0.36$ \\
\hline $\begin{array}{l}\text { d. salt: } \\
\text { MV: }\end{array}$ & $\begin{array}{c}2.165 \\
26.993\end{array}$ & $\frac{R f^{0}}{C^{0}}$ & $\frac{0.52}{0.93}=0.56$ & $\frac{0.36}{0.45}=0.80$ & $\frac{0.35}{0.64}=0.54$ & $\frac{0.26}{0.36}=0.72$ \\
\hline \multicolumn{7}{|c|}{ Sodium bromide $\mathrm{NaBr}=102.9($ d.: 3.203$) ; \mathrm{NaBr}, 2 \mathrm{H}_{2} \mathrm{O}=138.93(\text { d.: } 2.176)^{*}$} \\
\hline Molality & $\sqrt[3]{N \cdot M V}$ & $\sqrt[3]{\frac{N \cdot M V}{139}}$ & Orange G & Orange S & Tartrazine & Amaranth \\
\hline 1.12 & 0.210 & 0.040 & $0.60-0.64$ & $0.24-0.26$ & $0.29-0.30$ & $0.10-0.11$ \\
\hline 0.53 & 0.183 & 0.035 & $0.67-0.68$ & $0.27-0.29$ & $0.33-0.37$ & $0.13-0.14$ \\
\hline 0.26 & 0.154 & 0.030 & $0.71-0.74$ & $0.30-0.33$ & $0.38-0.42$ & $0.18-0.18$ \\
\hline 0.10 & 0.118 & 0.023 & $0.80-0.80$ & $0.35-0.38$ & $0.49-0.50$ & $0.24-0.25$ \\
\hline 0.05 & 0.095 & 0.018 & $0.82-0.83$ & $0.38-0.40$ & $0.52-0.55$ & $0.27-0.30$ \\
\hline 0.025 & 0.076 & 0.014 & $0.85-0.86$ & $0.42-0.44$ & $0.57-0.59$ & $0.32-0.38$ \\
\hline
\end{tabular}


Continued

\begin{tabular}{ccccccc}
\hline 0.010 & 0.056 & 0.010 & $0.88-0.92$ & $0.49-0.58$ & $0.72-0.76$ & $0.42-0.49$ \\
d. salt: & $\left.2.176^{*}\right)$ & $\frac{R f^{0}}{C^{0}}$ & $\frac{[0.54]}{[1.02]}=0.53$ & $\frac{0.40}{0.54}=0.74$ & $\frac{0.36}{0.73}=0.49$ & $\frac{0.26}{0.45}=0.58$ \\
MV: & 63.846 & & \\
\hline
\end{tabular}

$\mathrm{NaI}=149.8$ (d.: 3.667); $\mathrm{NIa}, 2 \mathrm{H}_{2} \mathrm{O}=185.92$ (d.: 2.448)* ${ }^{\star}$ Na I, $6 \mathrm{H}_{2} \mathrm{O}=258.07$

\begin{tabular}{|c|c|c|c|c|c|c|}
\hline Molality & $\sqrt[3]{N \cdot M V}$ & $\sqrt[3]{\frac{N \cdot M V}{258}}$ & Orange G & Orange S & Tartrazine & Amaranth \\
\hline 1.20 & 0.205 & 0.032 & $0.69-0.71$ & $0.32-0.35$ & $0.45-0.45$ & $0.15-0.17$ \\
\hline $0 . .55$ & 0.180 & 0.028 & $0.74-0.76$ & $0.37-0.37$ & $0.47-0.49$ & $0.18-0.20$ \\
\hline 0.26 & 0.152 & 0.024 & $0.76-0.78$ & $0.38-0.39$ & $0.50-0.52$ & $0.23-0.24$ \\
\hline 0.10 & 0.117 & 0.018 & $0.81-0.81$ & $0.40-0.42$ & $0.54-0.54$ & $0.27-0.31$ \\
\hline 0.05 & 0.095 & 0.015 & $0.85-0.86$ & $0.42-0.43$ & $0.59-0.60$ & $0.33-0.33$ \\
\hline 0.025 & 0.076 & 0.012 & $0.88-0.88$ & $0.46-0.46$ & $0.66-0.68$ & $0.34-0.35$ \\
\hline 0.010 & 0.056 & 0.009 & $0.90-0.92$ & $0.50-0.50$ & $0.71-0.77$ & $0.44-0.50$ \\
\hline $\begin{array}{l}\text { d. salt: } \\
\text { MV: }\end{array}$ & $\begin{array}{c}2.448^{(*)} \\
75.948\end{array}$ & $\frac{R f^{0}}{C^{0}}$ & $\frac{[0.65]}{[1.02]}=0.64$ & $\frac{0.51}{0.54}=0.94$ & $\frac{0.47}{0.73}=0.64$ & $\frac{0.32}{0.45}=0.71$ \\
\hline
\end{tabular}

The numbers [in square brackets] have been calculated.
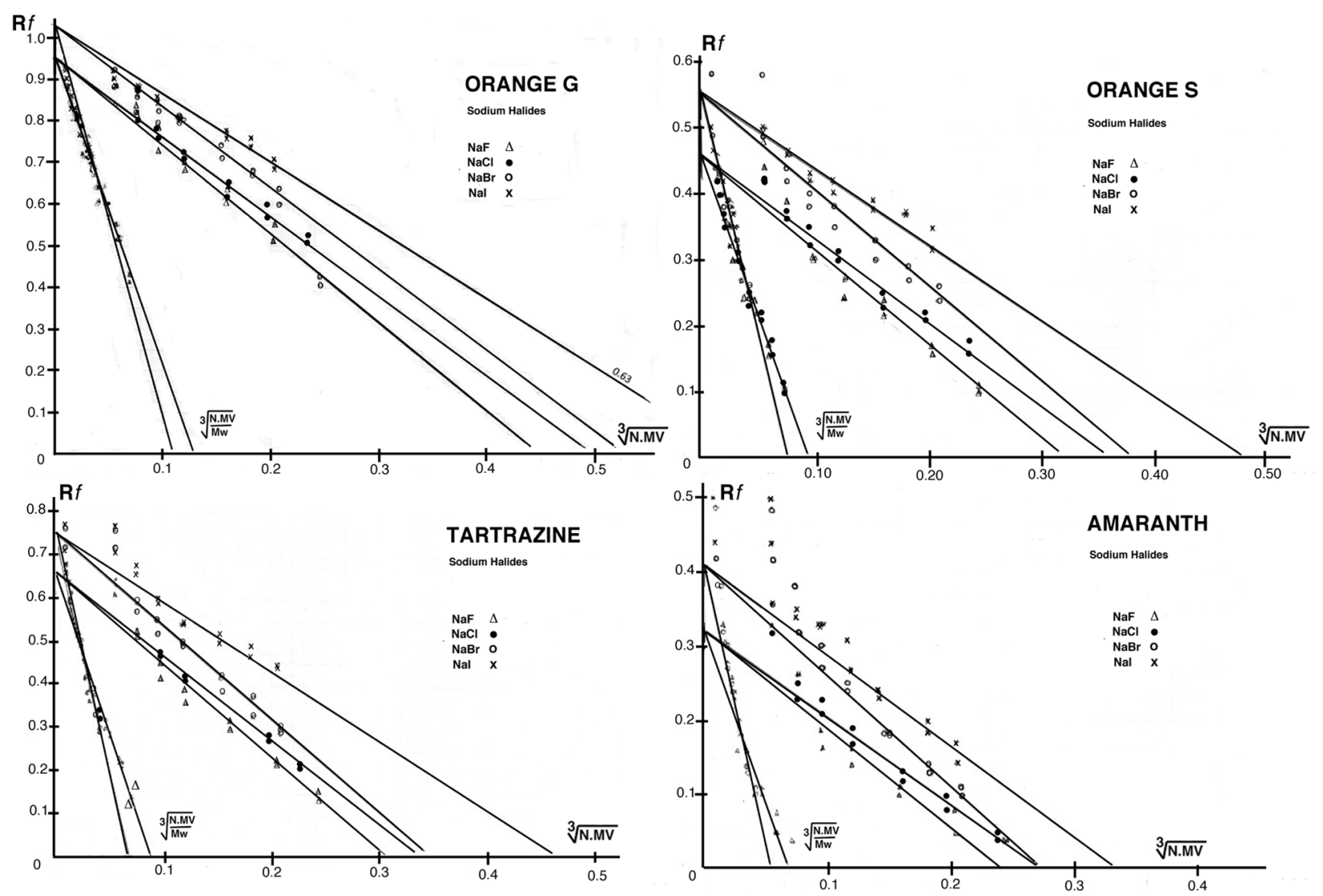

Figure 3. Curves of dyes and sodium halides. 
Table 3. Dyes and potassium halides constants as deduced from Equation (5).

\begin{tabular}{cccccc}
\hline Potassium & $\mathrm{Mw}$ & Orange G & Orange S & Tartrazine & Amaranth \\
\hline $\mathrm{KCl}$ & 74.56 & 0.095 & 0.142 & 0.090 & 0.147 \\
$\mathrm{KBr}$ & 119 & 0.094 & 0.142 & 0.089 & 0.142 \\
$\mathrm{KI}$ & 166 & 0.098 & 0.145 & 0.093 & 0.142 \\
& average & 0.095 & 0.143 & 0.090 & 0.143 \\
\hline
\end{tabular}

Table 4. Dyes and Sodium Halides constants as deduced from equation.

\begin{tabular}{cccccc}
\hline Sodium & $\mathrm{Mw}$ & Orange $\mathrm{G}$ & Orange $\mathrm{S}$ & Tartrazine & Amaranth \\
\hline $\mathrm{NaF}$ & $\mathbf{4 2}$ & $\mathbf{0 . 1 4 4}$ & $\mathbf{0 . 2 0 4}$ & $\mathbf{0 . 1 3 8}$ & $\mathbf{0 . 1 8 4}$ \\
$\mathrm{NaCl}$ & $\mathbf{5 8 . 4 4}$ & $\mathbf{0 . 1 4 4}$ & $\mathbf{0 . 2 0 6}$ & $\mathbf{0 . 1 3 9}$ & $\mathbf{0 . 1 8 5}$ \\
$\mathrm{NaBr}$ & 103 & 0.113 & 0.158 & 0.104 & 0.124 \\
$\mathrm{NaBr}, 2 \mathrm{H}_{2} \mathrm{O}$ & $\mathbf{1 3 9}$ & $\mathbf{0 . 1 0 2}$ & $\mathbf{0 . 1 4 3}$ & $\mathbf{0 . 0 9 3}$ & $\mathbf{0 . 1 0 8}$ \\
$\mathrm{NaI}$ & 150 & 0.120 & 0.177 & 0.120 & 0.133 \\
$\mathrm{NaI}, 2 \mathrm{H}_{2} \mathrm{O}$ & 186 & 0.112 & 0.164 & 0.112 & 0.124 \\
$\mathrm{NaI}, 6 \mathrm{H}_{2} \mathrm{O}$ & $\mathbf{2 5 8}$ & $\mathbf{0 . 1 0 0}$ & $\mathbf{0 . 1 4 7}$ & $\mathbf{0 . 1 0 0}$ & $\mathbf{0 . 1 1 1}$ \\
\hline
\end{tabular}

The numbers in bold highlight this difference between anhydrous and hydrated forms. The water of crystallization participates to the molecular volume while the water of solvation degreases the volume of free water. This technique makes it possible to specify the number of water molecules of crystallization or solvation of a salt. The values obtained with the potassium and sodium halides reveal a fairly good accuracy of the paper chromatography. However, with the very dilute eluent solutions, the added salts are adsorbed by the cellulose and the $\mathrm{Rf}$ tend to reach the $R f$ obtained in the case of pure water.

c) Relationship between molecular weight and $R f_{x}^{0} / C_{x}^{0}$.

The values of the quotients $R f^{\circ} / C^{\circ}$ is noted on graph paper (Figure 4) according to the molecular weight of the anhydrous salts to be comparable with each other, making it possible to determine new properties. In each diagram, the positive values of the vertical axis $R f / C$, are indicated at the top left, while the negative values are indicated at the bottom right and the molecular weights are noted on the $\mathrm{x}$-axis. When one observes a shift due to hydration, 2 or 4 molecules of water, by the lines are reported dashed.

Hydrated bromide and sodium iodide are "weighed down" by two molecules of water while anhydrous fluoride and sodium chloride are on the same straight line. By removing, by graphical construction upwards, the value of these two molecules of water these $R f$ are found on the same line as the anhydrous halides, thus validating our equations. But these values are not representative of bromide and sodium iodide; it is therefore necessary to remove the molecular weight of the water from the molecular weight of these two di-hydrated halides and the theoretical Mw of the anhydrous salt is found, then to connect this point to the representative curve of the anhydrous halides to obtain the theoretical $R f$ of anhydrous salt. It is then possible to connect these homogeneous values of sodium and potassium halides and to deduce new properties. This is confirmed by the calculation. These results are reported in Figure 4. 

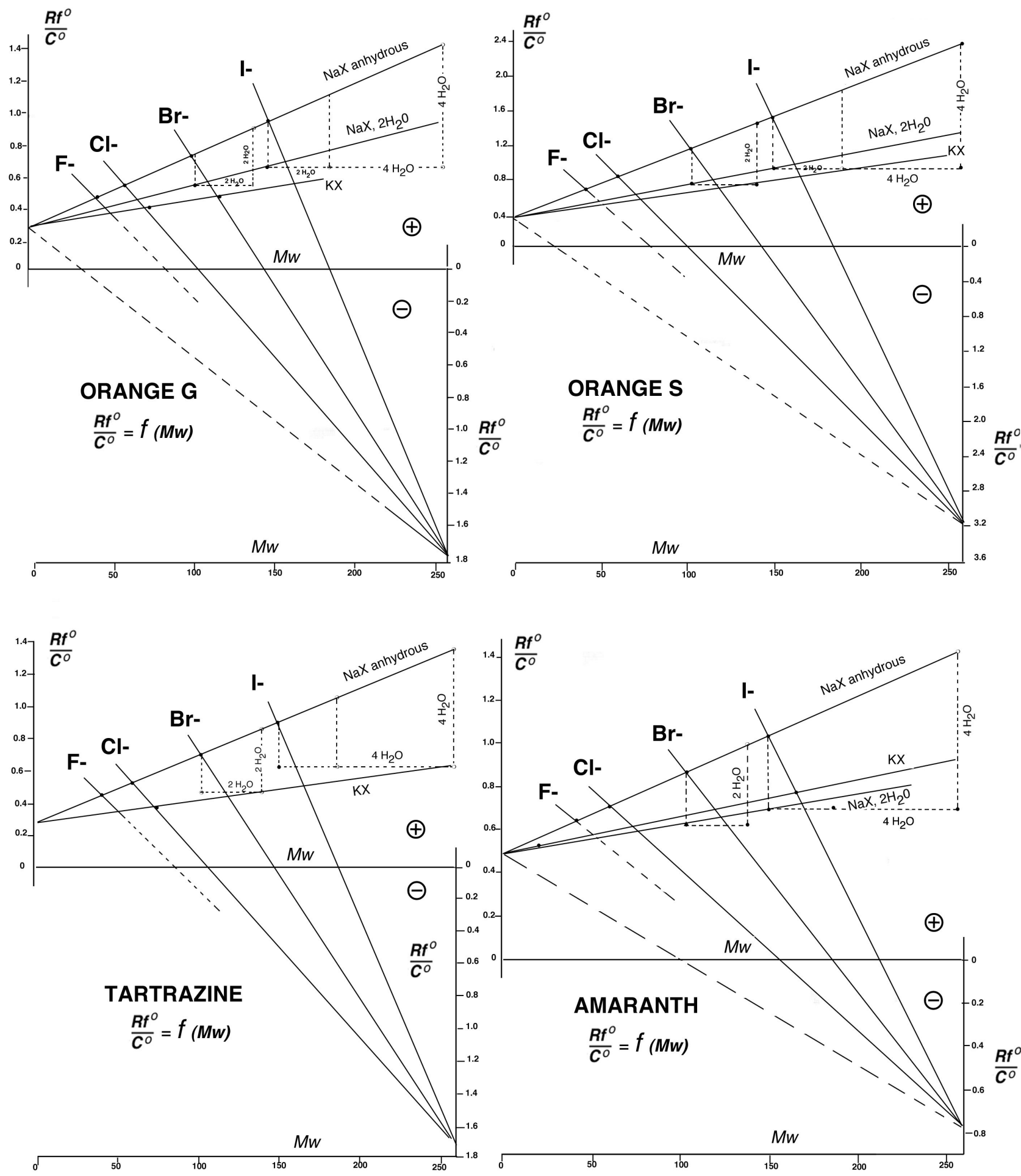

Figure 4. Relationship between molecular weight and $R f^{\circ} / C^{\circ}$ for the four dyes.

With Orange G. the $R f^{\circ} / C^{\circ}$ ratio of the anhydrous sodium and potassium halides are aligned on two lines which meet at the point 0.29 of the y-axis the bromide and the sodium iodide di-hydrated are aligned on another line which also reaches point 0.29. This makes possible to graphically complete the curve of the anhydrous salts. The straight lines of the anions meet on the right ordinate at the negative point 
-1.80 starting from the point 260 expressed in molecular weights. In the following case, these two concurrent points are noted $\oplus$ and $\ominus$, respectively.

Orange $S$ has the same appearance as the previous case. The straight lines of the sodium and potassium halide cations result in the value 0.38 on the left ordinate, while the lines of the anions meet on the right side at the negative point 3.20 on the right axis from the point 260 in terms of molecular weight. By the same graphical construction as above, the theoretical position of the $R f$ of the anhydrous bromide and iodide is determined on the same straight line as the fluoride and sodium chloride.

Tartrazine has the same arrangement as the other dyes. This arrangement makes it possible to determine, by the same graphical construction, the theoretical position of the bromide and of sodium iodide on the straight lines of the anhydrous halides and to obtain the value of the cations resulting in the point 0.28 on the left side and that of the anions at the negative point 1.72 on the right side.

With Amaranth, we also have equivalent aspect of the previous curves, the lines of the cations lead to the point 0.49 while the straight lines joining the anions, are found at the negative point of -0.77 on the ordinate of right.

The lines joining point's $\oplus$ and $\ominus$ (Figure 5) are plotted according to the molecular weights of the control dyes taking into account the electrical charge $e^{n+}$ of their acid functions evaluated arbitrarily at 1.00 according to the following Equation (7) deduced from Equation (5) and reported in Table 5.

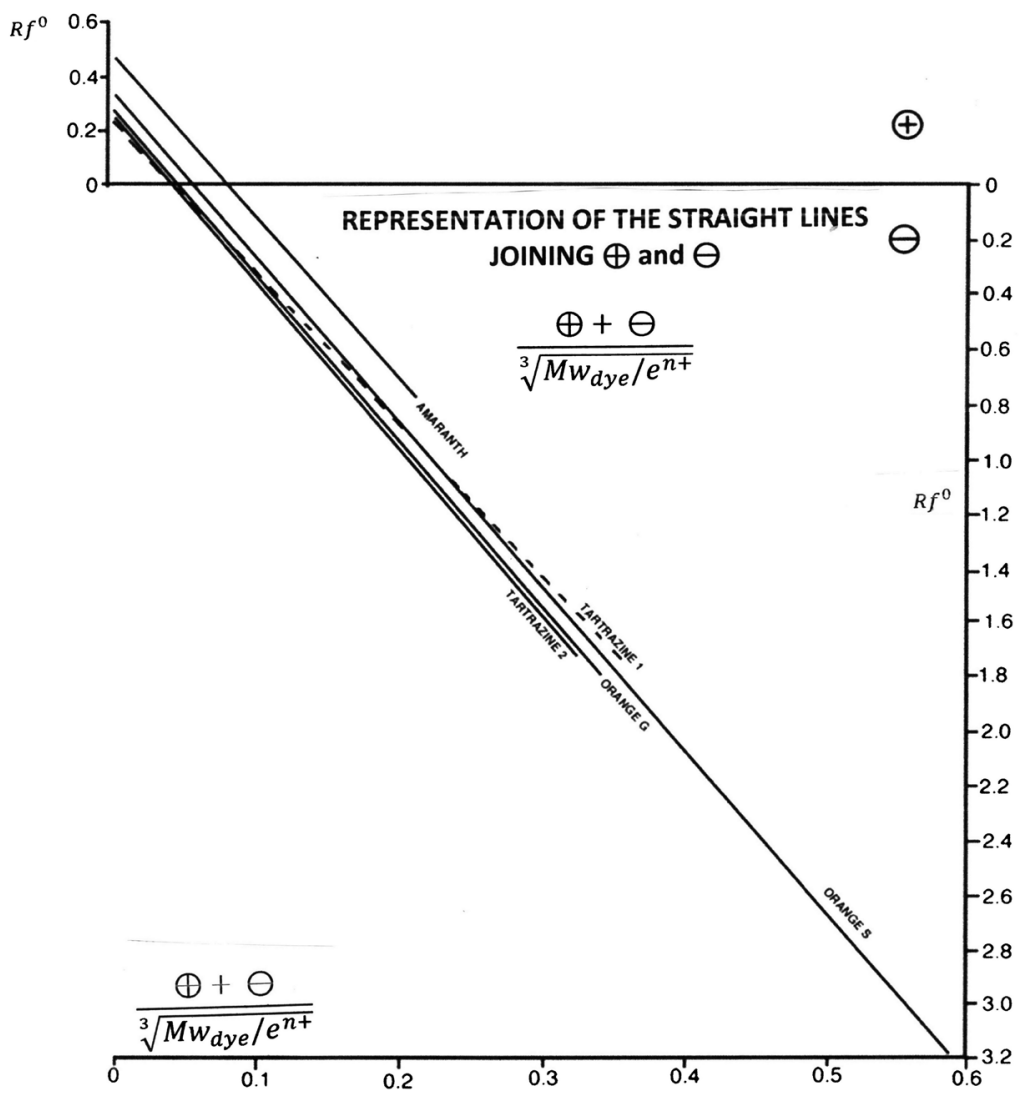

Figure 5. Representation of the straight lines joining $\oplus$ and $\ominus$. 
Table 5. Values of the straight lines joining $\oplus$ and $\ominus$.

\begin{tabular}{cccccc}
\hline dyes & $M w$ & $e^{n+}$ & $|\oplus|$ & $|\ominus|$ & $\frac{\oplus+\ominus}{\sqrt[3]{M w_{\text {dye }} / e^{n+}}}$ \\
\hline Orange G & 452.40 & 2 & 0.29 & 1.80 & 0.343 \\
Orange S & 452.40 & 2 & 0.38 & 3.20 & 0.587 \\
Tartrazine 1 & 534.36 & 3 & 0.28 & 1.72 & 0.355 \\
Tartrazine 2 & 534.36 & $2+\mathrm{x}$ & 0.28 & 1.72 & 0.326 \\
Amaranth & 607.50 & 3 & 0.49 & 0.77 & 0.214 \\
\hline
\end{tabular}

$$
\frac{\oplus+\ominus}{\sqrt[3]{M w_{d y e} / e^{n+}}}
$$

This big numerical difference between Orange $G$ and Orange $S$ does not seem normal because of their similarity of chemical structure (see further).

The four dyes were subjected to the same "pressure" because of the added salts, they move in parallel in this representation. However Tartrazine would not be parallel to the other three dyes. In fact, a value of 1.00 has been arbitrarily assigned to each salt function, but Tartrazine has two sulphonyl functions and a carboxylic function which does not have the same electrical value as the sulphonyl functions. By constructing the parallel of Tartrazine with those of the other dyes from point 0.28 this leads to the point 0.326 and not to the point 0.355 , which makes it possible to calculate the global value of $e^{n+}$ according to:

$$
\begin{gathered}
\frac{|0.28|+|1.72|}{\sqrt[3]{534.36 / e^{n+}}}=0.326 \\
e^{n+}=\frac{534.36}{(2.00 / 0.326)^{3}}=2.31
\end{gathered}
$$

The relative value of the potential of the carboxylic function is therefore 0.31 . This has been corrected in Figure 5 .

On the other hand, there is a big difference between the results of Orange G and Orange $S$ chromatographed by means of aqueous solutions of sodium and potassium halides. These two dyes have the same chemical structure (see Figure 1) and differ only in the position of their sulphone functions, the Orange $G$ in positions 7 and 9 , so very close, whereas in the orange $S$ ' the sulphone position 7 remains in place, while the sulfone function 9 migrates to the 4 ' position, far apart from each other.

The difference between these two values justifies the difference in behavior of these two dyes during the chromatographic analysis. However, if we had disposed of the molecular volume of our dyes, perhaps we would have justified this difference in behavior differently.

\subsubsection{Sodium Carboxylates (Aliphatic Acids)}

The same simple mathematical approach can be applied with success to some other 
salts, different from halides, for example to simple carboxylate salts and phosphates.

In the case of carboxylates, the density of sodium propionate is not available from the scientific literature, but its molecular volume can be extrapolated from the two curves whose molecular volumes are known (sodium formate and acetate):

NaHCOO: $\sqrt[3]{\frac{1}{35.421+55.509}}=0.222$

$\mathrm{NaCH}_{3} \mathrm{COO}: \sqrt[3]{\frac{1}{53.687+55.509}}=0.209$

The construction of the intersecting straight line joining these two points intercepts the propionate curve to its molar concentration, i.e. 0.199. Hence the molecular volume of the propionate calculated according to:

$$
M V=\frac{1-\left[55.509(0.199)^{3}\right]}{(0.199)^{3}}=71.385
$$

giving the density of the salt:

$$
\frac{96.06}{71.385}=1.345
$$

and the calculation of the molar concentration of sodium propionate is confirmed according to:

$$
\mathrm{NaCH}_{3} \mathrm{CH}_{2} \mathrm{COO}=\sqrt[3]{\frac{1}{71.385+55.509}}=0.199
$$

\begin{tabular}{|c|c|c|c|c|c|c|}
\hline \multicolumn{7}{|c|}{ Sodium Formate NaHCOO $=68.01$} \\
\hline Molality & $\sqrt[3]{N \cdot M V}$ & $\sqrt[3]{\frac{N \cdot M V}{1 / 68}}$ & Orange G & Orange S & Tartrazine & Amaranth \\
\hline 1.07 & 0.225 & 0.92 & 0.48 & 0.15 & 0.17 & 0.06 \\
\hline 0.52 & 0.191 & 0.78 & 0.58 & 0.19 & 0.24 & 0.09 \\
\hline 0.25 & 0.157 & 0.64 & 0.64 & 0.23 & 0.30 & 0.13 \\
\hline 0.10 & 0.119 & 0.48 & 0.74 & 0.29 & 0.38 & 0.17 \\
\hline 0.05 & 0.095 & 0.39 & 0.78 & 0.32 & 0.44 & 0.21 \\
\hline 0.025 & 0.076 & 0.30 & 0.81 & 0.64 & 0.50 & 0.25 \\
\hline 0.010 & 0.056 & 0.23 & 0.87 & 0.42 & 0.59 & 0.37 \\
\hline $\begin{array}{l}\text { d. salt: } \\
\text { MV: }\end{array}$ & $\begin{array}{c}1.92 \\
35.422\end{array}$ & $\frac{R f^{0}}{C^{0}}$ & $\frac{0.45}{0.98}=0.46$ & $\frac{0.33}{0.45}=0.73$ & $\frac{0.31}{0.61}=0.51$ & $\frac{0.27}{0.30}=0.90$ \\
\hline \multicolumn{7}{|c|}{ Sodium Acetate $\mathrm{NaCH}_{3} \mathrm{COO}=82.03$} \\
\hline molality & $\sqrt[3]{N \cdot M V}$ & $\sqrt[3]{\frac{N \cdot M V}{1 / 82}}$ & Orange $G$ & Orange $S$ & Tartrazine & Amaranth \\
\hline 1.09 & 0.212 & 0.92 & $0.43-0.47$ & $0.12-0.13$ & $0.13-0.14$ & $0.02-0.04$ \\
\hline
\end{tabular}

a) Experimental results for sodium carboxylates (aliphatic acids)

Table 6. Sodium Carboxylates. 


\section{Continued}

\begin{tabular}{|c|c|c|c|c|c|c|}
\hline 0.52 & 0.184 & 0.80 & $0.52-0.54$ & $0.16-0.17$ & $0.20-0.20$ & $0.06-0.08$ \\
\hline 0.25 & 0.154 & 0.67 & $0.59-0.63$ & $0.21-0.22$ & $0.26-0.27$ & $0.11-0.12$ \\
\hline 0.10 & 0.118 & 0.51 & $0.67-0.70$ & $0.26-0.27$ & $0.32-0.34$ & $0.15-0.16$ \\
\hline 0.05 & 0.095 & 0.41 & $0.75-0.76$ & $0.29-0.32$ & $0.36-0.38 T$ & $0.18-0.19$ \\
\hline 0.025 & 0.076 & 0.33 & $0.77-0.80$ & $0.32-0.38$ & $0.42-0.44$ & $0.23-0.25$ \\
\hline 0.010 & 0.056 & 0.24 & $0.85-0.86$ & $0.42-0.43$ & $0.61-0.64$ & $0.31-0.35$ \\
\hline d. salt: $M V$ : & $\begin{array}{c}1.528 \\
53.684\end{array}$ & $\frac{R f^{\circ}}{C^{\circ}}$ & $\frac{0.40}{0.98}=0.41$ & $\frac{0.29}{0.45}=0.64$ & $\frac{0.28}{0.61}=0.46$ & $\frac{0.24}{0.30}=0.80$ \\
\hline \multicolumn{7}{|c|}{ Sodium Propionate $\mathrm{NaCH}_{3} \mathrm{CH}_{2} \mathrm{COO}=96.08$} \\
\hline molality & $\sqrt[3]{N \cdot M V}$ & $\frac{N \cdot M V}{1 / 96}$ & Orange $G$ & Orange $S$ & Tartrazine & Amaranth \\
\hline 1.10 & 0.205 & 0.94 & 0.39 & 0.12 & 0.13 & 0.03 \\
\hline 0.52 & 0.179 & 0.82 & 0.51 & 0.14 & 0.18 & 0,06 \\
\hline 0.25 & 0.151 & 0.69 & 0.58 & 0.19 & 0.22 & 0.08 \\
\hline 0.10 & 0.117 & 0.54 & 0.68 & 0.25 & 0.30 & 0.12 \\
\hline 0.05 & 0.095 & 0.43 & 0.71 & 0.26 & 0.36 & 0.16 \\
\hline 0.025 & 0.076 & 0.34 & 0.75 & 0.32 & 0.45 & 0.21 \\
\hline 0.010 & 0.056 & 0.26 & 0.82 & 0.39 & 0.58 & 0.28 \\
\hline $\begin{array}{l}\text { d. salt. } \\
M V:\end{array}$ & $\begin{array}{c}{[1.345]} \\
{[71.385]}\end{array}$ & $\frac{R f^{\circ}}{C^{\circ}}$ & $\frac{0.38}{0.98}=0.39$ & $\frac{0.26}{0.45}=0.58$ & $\frac{0.24}{0.61}=0.39$ & $\frac{0.21}{0.30}=0.70$ \\
\hline
\end{tabular}

The numbers [in square brackets] from Table 6 of the propionate have been calculated (see above). To insert the curves of the reduction of concentrations by the inverse of the molecular weights on the same graph, the $\mathrm{x}$-axis is superimposed by another scale noted from zero to two.

The distribution of these curves is opposite to that obtained by means of themineral salts and the Equation (5) is written according to

$$
R f_{0}^{0}=\frac{R f_{x}^{0} / C_{x}^{0}}{\sqrt[3]{1 / \sqrt[3]{M w_{x}}}}
$$

To insert the curves of the reduction of concentrations by the inverse of the molecular weight on the same graph, the $\mathrm{x}$-axis is superimposed by another scale noted from zero to two. They are reported in Figure 6.

The results are reported in Table 7.

According to Equation (10), sodium propionate would form a monohydrate or would capture a molecule of solvating water.

b) Relationship between $M w$ and $R f^{0} / C^{0}$

The ratio $R f_{x}^{0} / C_{x}^{0}$ of the dyes developed by solutions of sodium formate, 
acetate and propionate are aligned, this leads to the point $M w 205$ on the x-axis, according to Figure 7:

$$
\frac{R f_{x}^{0} / C_{x}^{0}}{205-M w_{x}}=k_{x}
$$

Table 7. Dyes and Sodium Carboxylates (fatty acids) constants.

\begin{tabular}{cccccc}
\hline & Mw & Orange G & Orange S & Tartrazine & Amaranth \\
\hline $\mathrm{NaHCOO}$ & 68.01 & 1.75 & 2.98 & 2.08 & 3.67 \\
$\mathrm{NaCH}_{3} \mathrm{COO}$ & 82.03 & 1.74 & 2.78 & 2.00 & 3.47 \\
$\mathrm{NaCH}_{3} \mathrm{CH}_{2} \mathrm{COO}$ & 96.06 & 1.69 & 2.65 & 1.78 & 3.20 \\
$\mathrm{NaCH}_{3} \mathrm{CH}_{2} \mathrm{COO} \cdot \mathrm{H}_{2} \mathrm{O}$ & 114.07 & 1.79 & 2.81 & 1.89 & 3.39 \\
& average & 1.76 & 2.85 & 1.99 & 3.51 \\
\hline
\end{tabular}
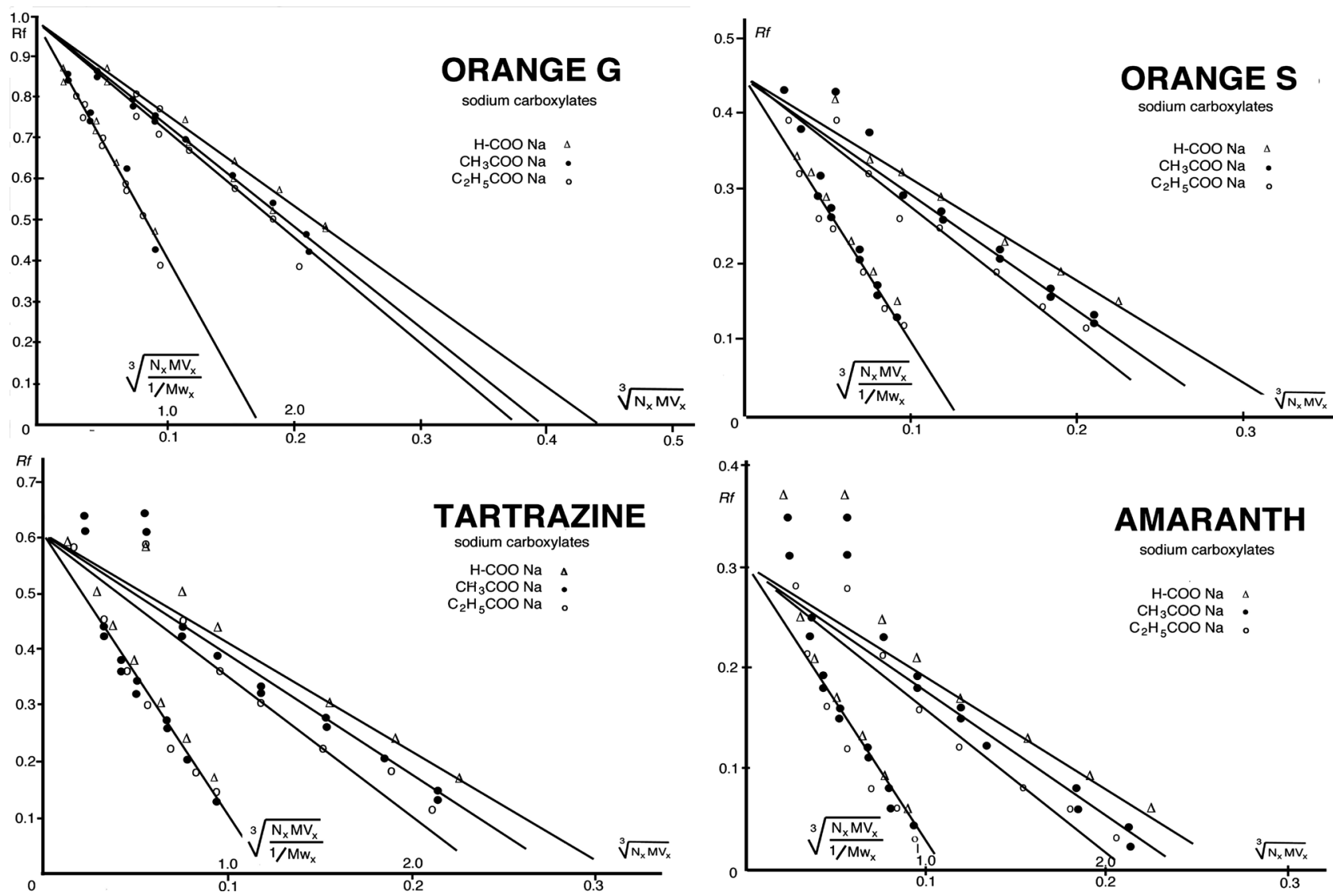

Figure 6. Curves of dyes and sodium carboxylates.

On the other hand, it appears proportionality between the lengths of the carbon chain added with the salifying atom according to the empirical equation:

$$
\frac{M V}{N b . o f C+N a}
$$

NaHCOO: $\frac{35.422}{2}=17.71$ 
$\mathrm{NaCH}_{3} \mathrm{COO}: \frac{53.684}{3}=17.89$

$\mathrm{NaCH}_{3} \mathrm{CH}_{2} \mathrm{COO}, \mathrm{H}_{2} \mathrm{O}: \frac{71.385}{4}=17.84$

These results confirm the existence of a sodium propionate monohydrate.

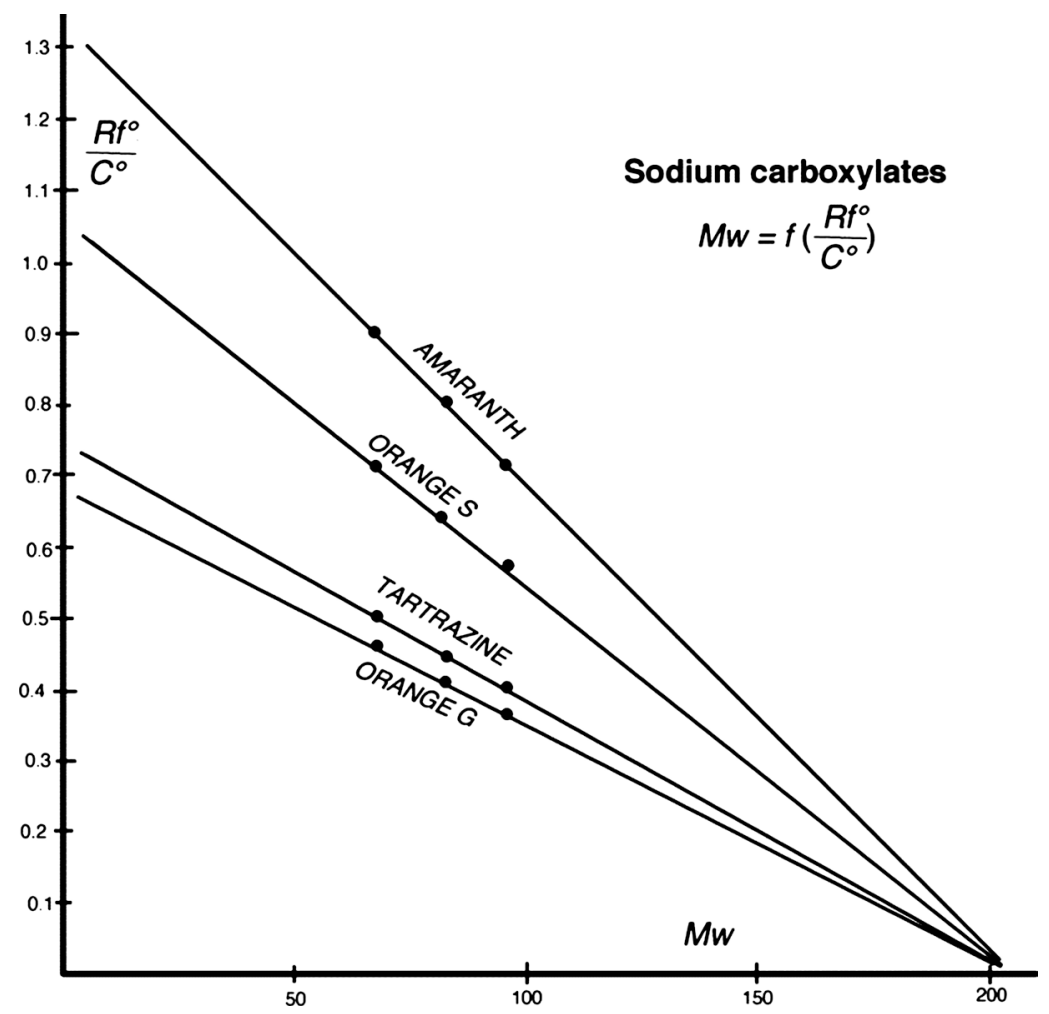

Figure 7. Relation between the $M W$ of sodium carboxylate and $R f^{0} / C^{0}$.

\subsubsection{Phosphates of Monovalent Salts}

The results observed with aqueous solutions of phosphates bring new elements to the limits and possibilities of the chromatographic analysis we present here. To compare the behavior of the different dyes, one must take into account the water of hydration and the number of cations salifying the phosphoric acid according to Equation (3):

$$
\sqrt[3]{\left.\left[\frac{N_{1}}{\left[M^{+}\right.}\right) M V_{1}+\frac{1000-\left[\left(\frac{N_{1}}{n M^{+}}\right) 18.015 n\right]}{18.015}\right]}
$$

The $R f$ of potassium and sodium phosphates are given in Table 8 and Table 9.

\section{a) Potassium Orthophosphates}

The literature does not give the density of hygroscopic and amorphous di-potassium phosphate. During this study we have established that, as for the same homologous series of halides, the $C_{x}^{0}$ is common and the $R f_{x}^{0}$ is determined according to: 


$$
R f_{x}^{0}=C_{0}^{0} \cdot \sqrt[3]{M w_{x} / n M^{+}}
$$

This gives, for the Orange $\mathrm{G}$ chromatographed by the solutions of the three potassium phosphates, a $R f_{0}^{0}=0.066$ and a $C_{0}^{0}=0.89$ :

$$
\begin{array}{rrr} 
& R f_{x}^{0} & R f_{x}^{0} / C_{0}^{0} \\
\mathrm{KH}_{2} \mathrm{PO}_{4}: & 0.066 \sqrt[3]{136}=0.34 & 0.34 \div 0.89=0.38 \\
\mathrm{~K}_{2} \mathrm{HPO}_{4}: 0.066 \sqrt[3]{174 / 2}=0.29 & 0.29 \div 0.89=0.33 \\
\mathrm{~K}_{3} \mathrm{PO}_{4}: 0.066 \sqrt[3]{212 / 2}=0.27 & 0.27 \div 0.89=0.30
\end{array}
$$

Which allows drawing the theoretical curve of potassium tri-phosphate as it was described for the previously in the case of the sodium propionate:

$$
\begin{aligned}
& \mathrm{KH}_{2} \mathrm{PO}_{4}: \sqrt[3]{\frac{1}{58.208+55.509}}=0.206 \\
& \mathrm{~K}_{3} \mathrm{PO}_{4}: \sqrt[3]{\frac{1}{73.317+55.509}}=0.198
\end{aligned}
$$

By graphical construction, the line intersecting these two points cuts the curve of potassium mono-phosphate at its molar concentration, i.e. -0.198 . Hence its molecular volume can be calculated according to Equation (9):

$$
M V=\frac{1-\left[55.509(0.198)^{3}\right]}{(0.198)^{3}}=73.317
$$

hence the density of salt:

$$
d=\frac{\mathbf{1 7 4 . 1 8}}{\mathbf{7 3 . 3 1 7}}=2.375
$$

Table 8 makes it possible to construct the curves Figure 8:
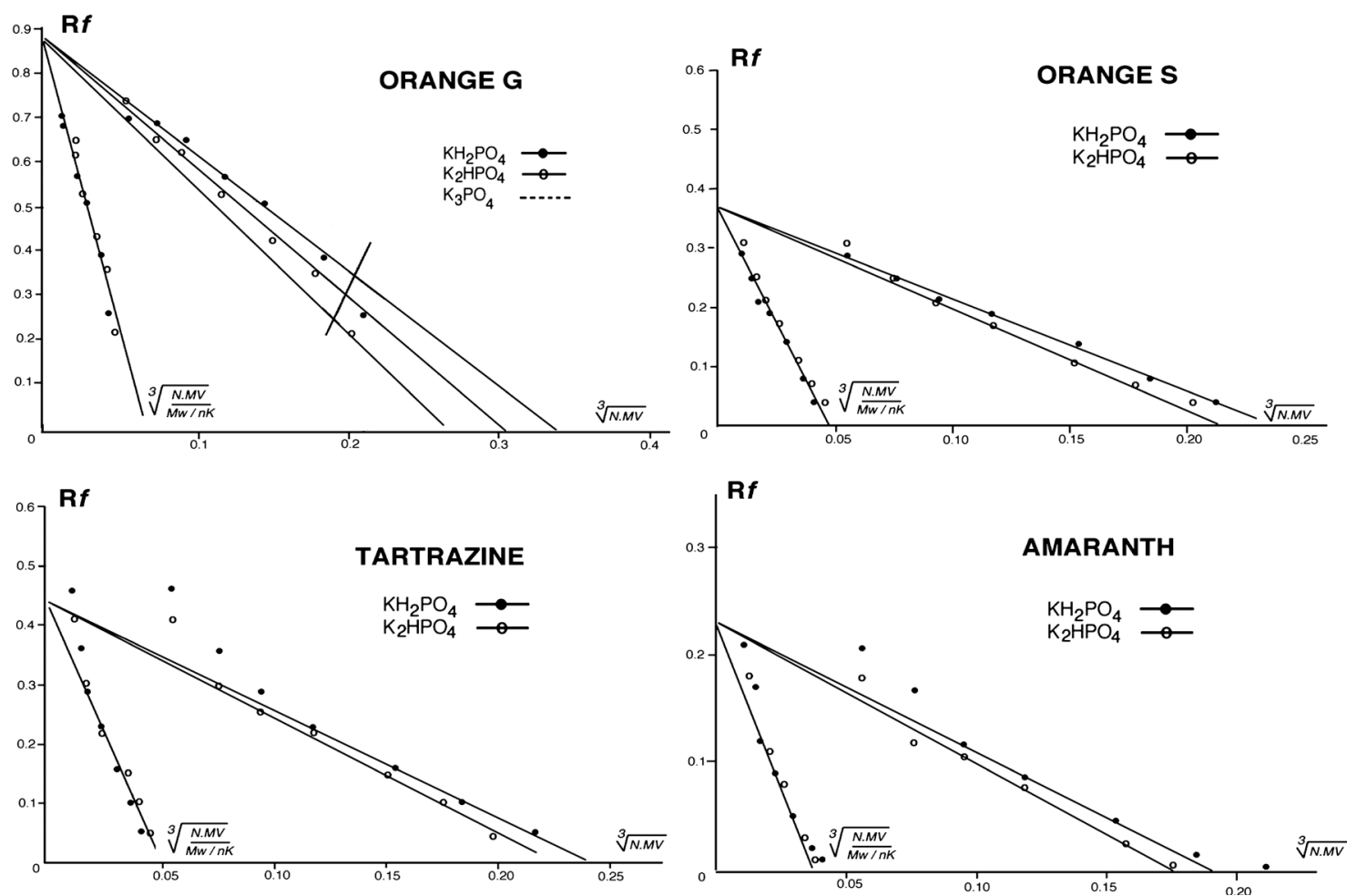

Figure 8. Curves of dyes and Potassium orthophosphates. 
Table 8. Dyes and Potassium orthophosphates.

Potassium orthophosphate di-acid $\mathrm{KH}_{2} \mathrm{PO}_{4}=136.09$

\begin{tabular}{ccccccc}
\hline Molality & $\sqrt[3]{N \cdot M V}$ & $\sqrt[3]{\frac{N \cdot M V}{136}}$ & Orange G & Orange S & Tartrazine & Amaranth \\
\hline 1.20 & 0.212 & 0.041 & 0.26 & 0.04 & 0.05 & 0.01 \\
0.55 & 0.184 & 0.036 & 0.39 & 0.08 & 0.10 & 0.02 \\
0.26 & 0.154 & 0.030 & 0.51 & 0.14 & 0.16 & 0.05 \\
0.10 & 0.118 & 0.023 & 0.57 & 0.19 & 0.23 & 0.09 \\
0.05 & 0.096 & 0.018 & 0.65 & 0.21 & 0.29 & 0.12 \\
0.025 & 0.076 & 0.015 & 0.69 & 0.25 & 0.36 & 0.17 \\
0.010 & 0.056 & 0.011 & 0.70 & 0.29 & 0.47 & 0.21 \\
d. salt: & 2.338 & $\frac{R f^{0}}{C^{0}}$ & $\frac{0.33}{0.89}=0.37$ & $\frac{0.24}{0.37}=0.65$ & $\frac{0.24}{0.44}=0.54$ & $\frac{0.20}{0.23}=0.87$ \\
MV: & 58.208 & &
\end{tabular}

Potassium Orthophosphate mono-acid $\mathrm{K}_{2} \mathrm{HPO}_{4},=174.18$

\begin{tabular}{ccccccc}
\hline Molality & $\sqrt[3]{N \cdot M V}$ & $\sqrt[3]{\frac{N \cdot M V}{174 / 2}}$ & Orange G & Orange S & Tartrazine & Amaranth \\
\hline 1.26 & 0.204 & 0.046 & 0.22 & 0.04 & 0.04 & 0.00 \\
0.57 & 0.180 & 0.040 & 0.36 & 0.08 & 0.10 & 0.01 \\
0.27 & 0.153 & 0.034 & 0.44 & 0.12 & 0.15 & 0.03 \\
0.105 & 0.118 & 0.026 & 0.53 & 0.17 & 0.22 & 0.08 \\
0.052 & 0.096 & 0.021 & 0.62 & 0.21 & 0.26 & 0.11 \\
0.026 & 0.076 & 0.017 & 0.65 & 0.24 & 0.30 & 0.12 \\
0.010 & 0.056 & 0.012 & 0.75 & 0.31 & 0.74 & 0.18 \\
d. salt: & {$[2.37]$} & $\frac{R f^{0}}{C^{0}}$ & $\frac{0.30}{0.89}=0.34$ & $\frac{0.22}{0.37}=0.59$ & $\frac{0.225}{0.44}=0.51$ & $\frac{0.18}{0.23}=0.78$ \\
MV: & {$[73.317]$} & & & & & 0.12 \\
\hline
\end{tabular}

Figures in [square brackets] have been calculated.

Dyes chromatographed with aqueous solutions of potassium phosphates, which do not have hydrated form confirm the previous results.

b) Sodium Orthophosphates.

The same analysis holds for sodium mono and di-phosphates with however a more extensive results.

The curves of sodium mono and di-phosphates, after reduction by their respective molecular weights, are found on the same line (Figure 9). Sodium tri-phosphate which is very alkaline in solution produces however non-linear curves with a rapid rise in $R f$ followed by a sharp drop and then a rise along the sodium di-phosphate curve to reach the common $C^{\circ}$. During elution, some of the alkali binds to the cellulose and modifies its properties according to the principle of mercerizing of cotton. For the diluted solutions, no free ions remain and hence the corresponding curve returns back to the sodium di-phosphate curve. 
Table 9. Dyes and sodium orthophosphates.

$\left[\mathrm{NaH}_{2} \mathrm{PO}_{4}=119.98\right] ; \mathrm{NaH}_{2} \mathrm{PO}_{4}, 2 \mathrm{H}_{2}=156.01$

\begin{tabular}{ccccccc}
\hline Molality & $\sqrt[3]{N \cdot M V}$ & $\sqrt[3]{\frac{N \cdot M V}{156}}$ & Orange G & Orange S & Tartrazine & Amaranth \\
\hline 1.22 & 0.208 & 0.039 & 0.33 & 0.06 & 0.08 & 0.01 \\
0.56 & 0.177 & 0.033 & 0.47 & 0.13 & 0.125 & 0.05 \\
0.27 & 0.152 & 0.028 & 0.55 & 0.15 & 0.23 & 0.08 \\
0.104 & 0.118 & 0.22 & 0.63 & 0.23 & 0.31 & 0.12 \\
0.052 & 0.095 & 0.018 & 0.69 & 0.26 & 0.37 & 0.16 \\
0.026 & 0.076 & 0014 & 0.72 & 0.31 & 0.41 & 0.19 \\
0.010 & 0.056 & 0.010 & 0.82 & 0.40 & 0.56 & 0.30 \\
d. salt: & 1.91 & $\frac{R f^{0}}{C^{0}}$ & $\frac{0.35}{0.95}=0.37$ & $\frac{0.24}{0.45}=0.53$ & $\frac{0.25}{0.59}=0.42$ & $\frac{0.21}{0.29}=0.72$ \\
MV: & 81.680 & & & & & 0.35 \\
\hline
\end{tabular}

$\left[\mathrm{Na}_{2} \mathrm{HPO}_{4}=141.96\right]: \mathrm{Na}_{2} \mathrm{HPO}_{4}, 7 \mathrm{H}_{2} \mathrm{O}=268.07$

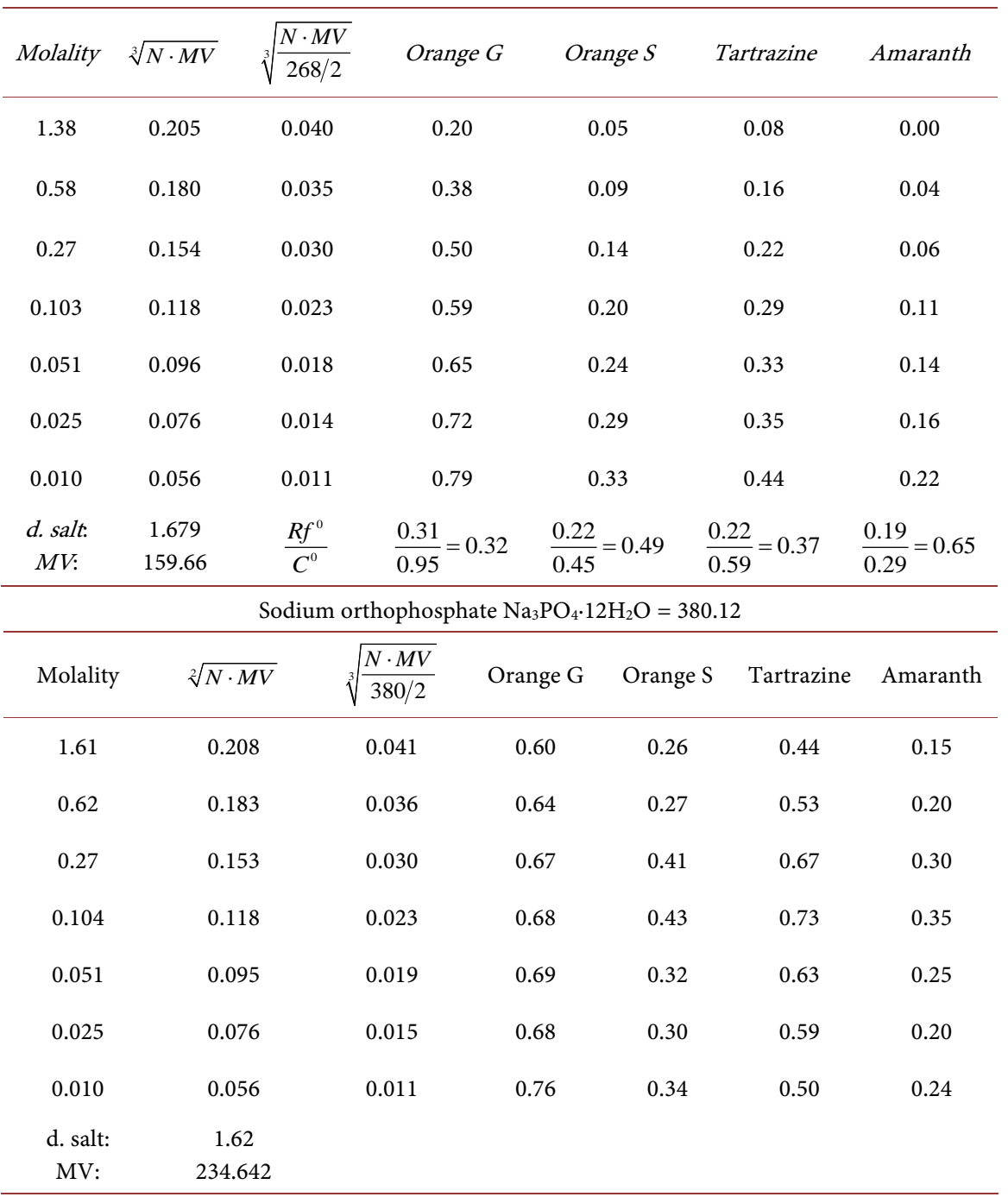



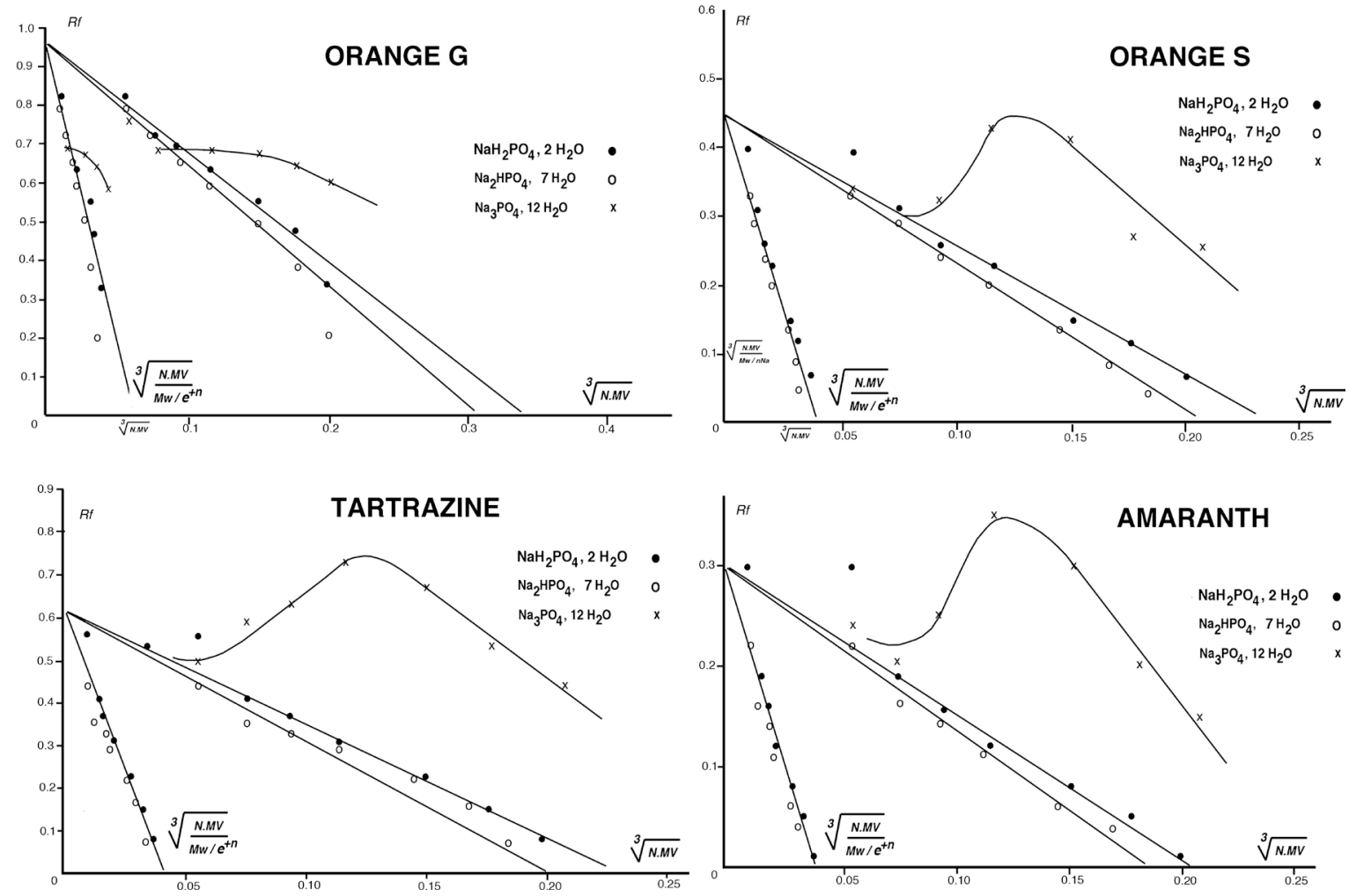

Figure 9. Curves of dyes and Sodium orthophosphates.

c) Relationship between $M w$ and $R f^{0} / C^{0}$.

To compare these results, it is necessary to unify the values of the various phosphates more or less hydrated by reducing them to their anhydrous forms. As for halides, the relationship of the molecular weight of the phosphates with the quotient $R f^{0} / C^{0}$ reveals interesting properties according to the following curves Figure 10 .
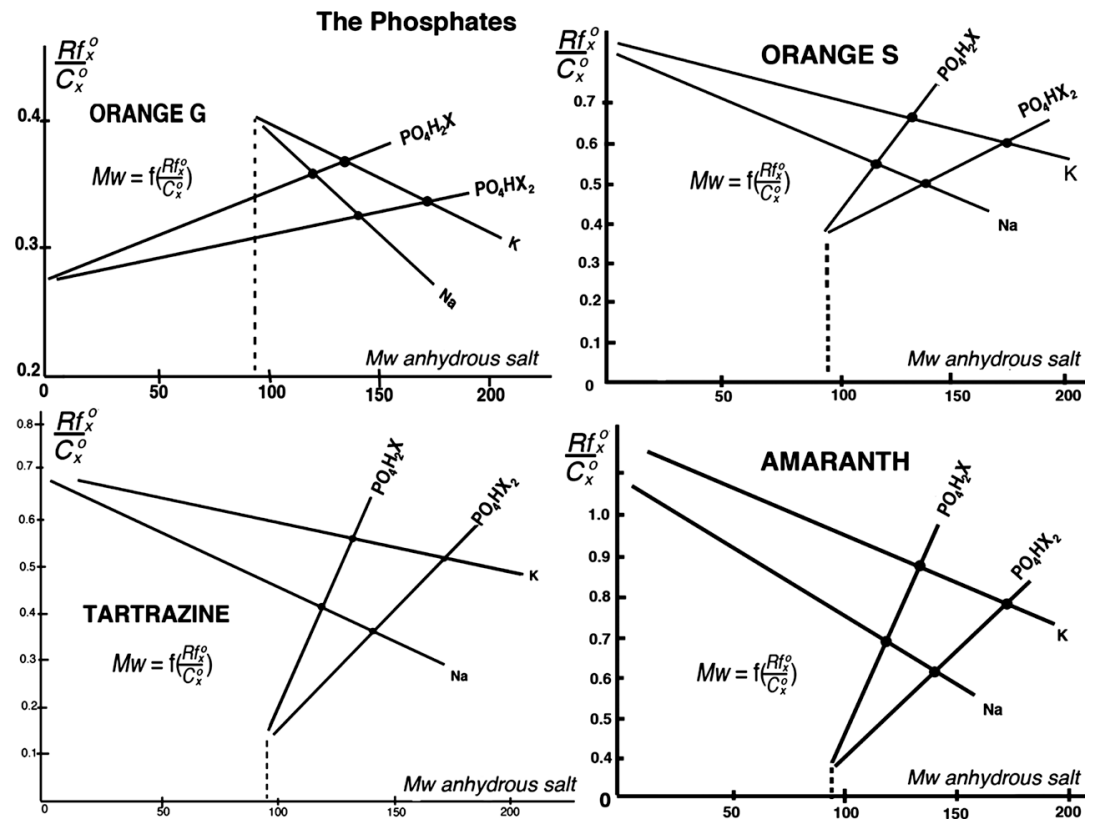

Figure 10. Relationship between $M w$ and $R f_{x}^{0} / C_{x}^{0}$ of Na and $\mathrm{K}$ Phosphates. 
With Orange $\mathrm{G}$, the lines of the ratio $R f_{x}^{0} / C_{x}^{0}$ of the sodium and potassium di-acid and mono-acid phosphates meet at the point 95 of the $\mathrm{x}$-axis corresponding to the molecular weight of the tri-anion $\mathrm{PO}_{4}^{3-}=94.97$. while the straight lines joining the sodium and potassium phosphates meet at the point 0.28 on the $\mathrm{y}$-axis of $R f$ s to a value corresponding to the water empty of salts.

With the other three dyes, it is the mono and di-hydrated phosphates which cross at point 95 of the abscissa axis, while the straight lines of sodium and potassium phosphates meet on the left ordinate, at the exception of Amaranth, whose $R f$ are very small, which increases the error inherent to the method, hence the uncertainty of their meeting point. These quotient values $R f_{x}^{0} / C_{x}^{0}$ are given below:

Orange G; 0.28 .

Orange S: 0.85 .

Tartrazine: 0.67 .

Amaranth: between 1.15 and 1.25.

... In the chapter on sodium and potassium halides, we observed a big difference between the Rf of sodium and potassium halides, which we thought was abnormal, and we hypothesized that Orange G, in aqueous solution, had only one sodium atom, the latter being wedged between the two sulphonyl functions situated in position 7 and 9. This observation could explain this difference in behavior.

All these curves confirm the previous results, with the exception of the highly alkaline tri sodium phosphate which transform the propertied of paper cellulose.

\subsection{Organic Solvents}

Previous mathematical results have been compared with those obtained with pure or mixed organic solvents. In this study, Fructose a non-ionic substance is used as a control for $R f$ variations.

Fructose (in $0.1 \%$ aqueous solution) is revealed by spraying a mixture of benzidine $(0.50 \mathrm{~g})+$ acetic acid $(20 \mathrm{ml})+$ water $(80 \mathrm{ml})$, then dried in air, followed by a second spray with alcoholic solution of $3 \%$ hydrochloric acid and heated in an oven at $105^{\circ} \mathrm{C}$ for 2 minutes.

\subsubsection{Pure Organic Solvents}

The carboxylic acids are differentiated in their behavior between two possible forms in organic solvents:
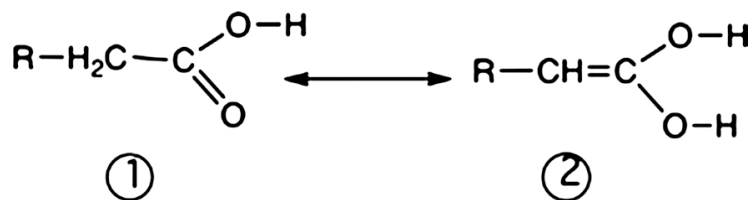

By migration of an $\mathrm{H}$ noted (1) from a neighboring $\mathrm{CH}_{2}$, giving equal mobility to the two hydrogen atoms noted (2) in their association, which experience confirms. The elemental constants of some simple organic solvent in use in this study are reported in Table 10 make it possible to construct the curves 11 . 
Table 10. Properties of some organic solvent.

\begin{tabular}{cccccc}
\hline Solvents & $\mathrm{Mw}$ & densities & $\mathrm{MV}$ & $(-\mathrm{OH}) \%$ & $R f$ of Fructose \\
\hline Water & 18.015 & 1.0000 & 18.015 & 94.45 & 0.98 \\
Methanol & 32.04 & 0.7914 & 40.49 & 53.13 & 0.50 \\
Ethanol & 46.07 & 0.7893 & 58.37 & 36.94 & 0.24 \\
Propanol & 60.11 & 0.8035 & 74.81 & 28.31 & 0.00 \\
Butanol & 74.12 & 0.8098 & 91.53 & 22.96 & 0.00 \\
& & & & (1) 36.97 & - \\
Formic ac. & 46.03 & 1.220 & 37.73 & (2) 73.94 & 0.86 \\
& & & & (1) 28.34 & - \\
Acetic ac. & 60.05 & 1.0492 & 57.23 & (2) 56.68 & 0.58 \\
& & & & (1) 22.97 & - \\
Propionic ac & 74.08 & 0.9930 & 74.60 & (2) 45.94 & $0.38\left(^{*}\right)$ \\
& & & & (1) 19.31 & - \\
Butyric ac. & 88.12 & 0.9577 & 92.01 & (2) 38.64 & 0.00 \\
\hline
\end{tabular}

${ }^{*}$ ) Propionic acid has a spot of $R f=0.38$ followed by a long tail.

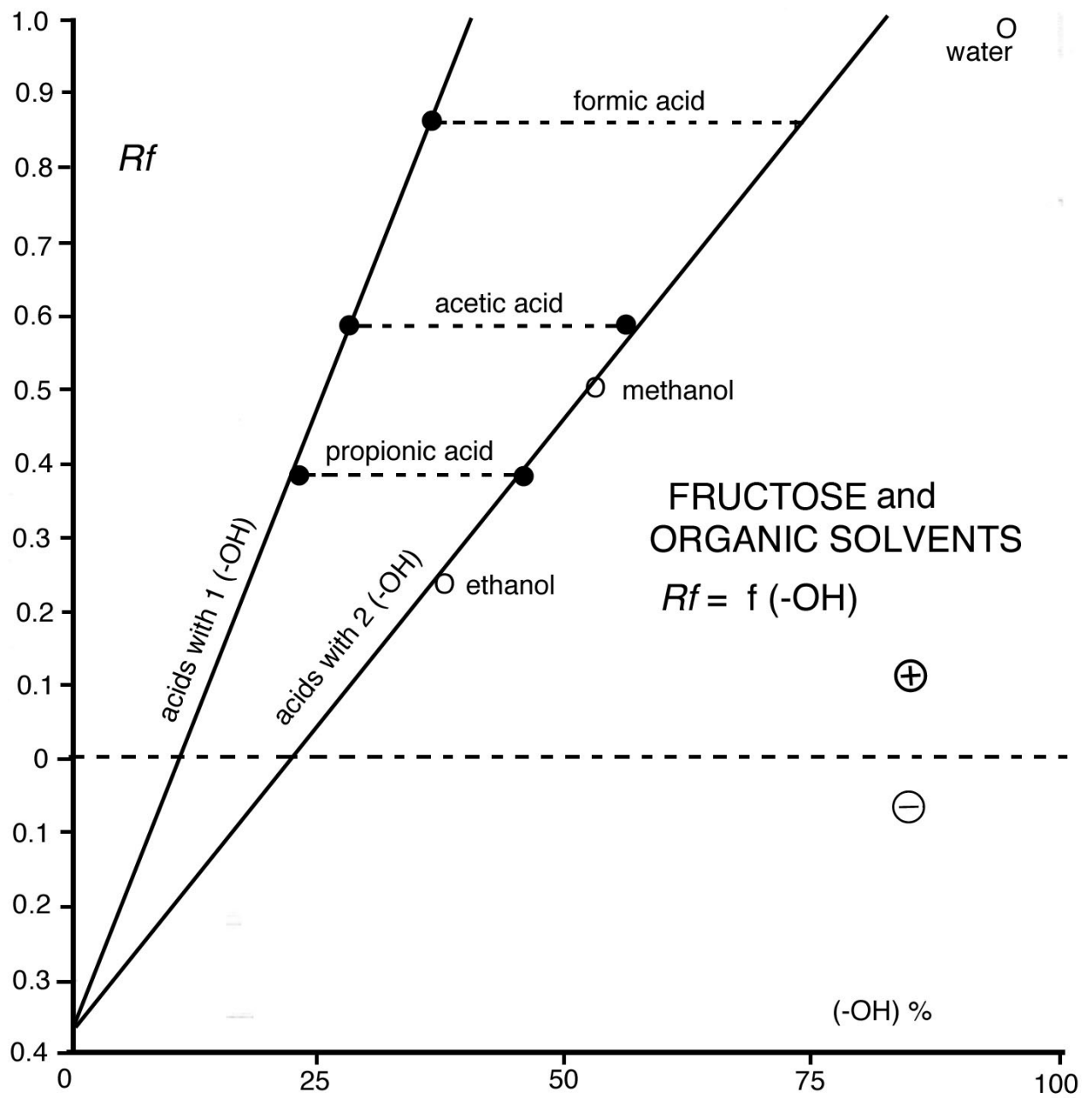

Figure 11. Behavior of $R f$ of Fructose with pure organic solvents. 
We observe (Figure 11) two straight lines that meet on the extended the y-axis of the extended $R f$ in negative values at the point 0.38 . The $R f$ values of Fructose are proportional to the percentage of hydroxyl functions present in the molecules of pure solvents noted (2). The $R f$ obtained with the acids considered with two hydroxyls are on the same straight line as the alcohols, which confirms the migration of hydrogen. The hydrophilic (-OH) fractions (Figure 11) of alcohols and pure organic acids behave as solvent solutions containing non-solvent solutions of one, two or three $\left(-\mathrm{CH}_{2}\right)$. Pure organic solvents can therefore be assimilated to perfect theoretical solutions.

\subsubsection{Binary Organic Solvents}

The organic solvents saturate the chromatographic chamber, causing a continuous movement of evaporation/condensation between the vapors and the rising liquid. If the constituents have different volatilities, the composition of the vapor will be different from that of the eluent, thus complicating the understanding of the phenomenon. By adjusting the formulation of the solvent mixtures as a function of the composition of their vapors saturating the chromatographic chamber, according to reference [11] more consistent results are obtained. The organic solvent mixtures are calculated according to Dalton's law. By operating at ambient temperature and at atmospheric pressure, the relationship is simplified:

$$
m=d \times F
$$

where $m$ is the mass of volatile solvent necessary to saturate the chromatographic chamber. $d$ the density of the vapor at $20^{\circ} \mathrm{C}$ and $F$ the vapor pressure at $20^{\circ} \mathrm{C}$. It suffices to add these masses and determine their percentage in relation to their sum to obtain the composition of the mixture used, whether binary, ternary or more. The vapor densities of alcohols and organic acids are found on the same line determined according to:

$$
\frac{M w}{\text { d.vapor }}=28.68
$$

This relationship makes it possible to calculate the vapor densities at $20^{\circ} \mathrm{C}$ (Figure 13) and to compare them with those given by the scientific literature. These are noted in bold or underlined in Table 11, Table 12 and Figure 12.

\begin{tabular}{|c|c|c|}
\hline & Water & $18.015: 0.622=28.96$ \\
\hline \multirow[t]{5}{*}{ Alcohols } & Methanol & $32.042: 1.12=28.61$ \\
\hline & Ethanol & $46.048: 1.6=28.79$ \\
\hline & Propanol & $60.95: 2.1=28.62$ \\
\hline & Butanol & $74.121: 2.6=28.51$ \\
\hline & Pentanol & $88.148: 3.05=28.91$ \\
\hline
\end{tabular}

Table 11. Determination of vapor densities at $20^{\circ} \mathrm{C}$. 
Continued

\begin{tabular}{cll}
\hline Fliphatic acids & Formic acid & $46.026: 1.6=28.77$ \\
Acetic acid & $\mathbf{6 0 . 0 5 2 : 2 . 7}=\mathbf{2 9 . 0 0}$ \\
Propionic acid & $74.079: 2.6=28.49$ \\
Butyric acid & $88.106: 3.1=28.42$ \\
Valerianic acid & $102.132: 3.6=28.37$ \\
Average & 28.68 \\
\hline
\end{tabular}

Table 12. Densities and vapor pressure at $20^{\circ} \mathrm{C}$ of some organic solvents.

\begin{tabular}{ccccc}
\hline Solvents & Mw & \multicolumn{3}{c}{$\begin{array}{c}\text { Densities (1) Pressures (2) } \\
\text { of vapors }\end{array}$} \\
\hline Water & 18.015 & 0.622 & 17.535 & $\mathrm{~d} \times \mathrm{F}$ \\
Methanol & 32.04 & 1.12 & 96.0 & 107.52 \\
Ethanol & 46.07 & 1.6 & 43.9 & 70.24 \\
Propanol & 60.11 & 2.1 & 14.5 & 30.45 \\
Butanol & 74.12 & 2.6 & 4.3 & 11.18 \\
Pentanol & 88.15 & 3.05 & 2.8 & 8.54 \\
Formic acid & 46.03 & 1.6 & 29.0 & 46.40 \\
Acetic acid & 60.05 & 2.07 & 15.5 & 32.08 \\
Propionic acid & 74.09 & 2.6 & 2.9 & 7.54 \\
Butyric acid & 88.12 & 3.1 & 0.75 & 2.32 \\
\hline
\end{tabular}

(1) Handbook of Chemistry and Physics (50 $0^{\text {th }}$ Ed. 1969-1970); (2) T E Jordan: Vapor pressures of organic solvents.

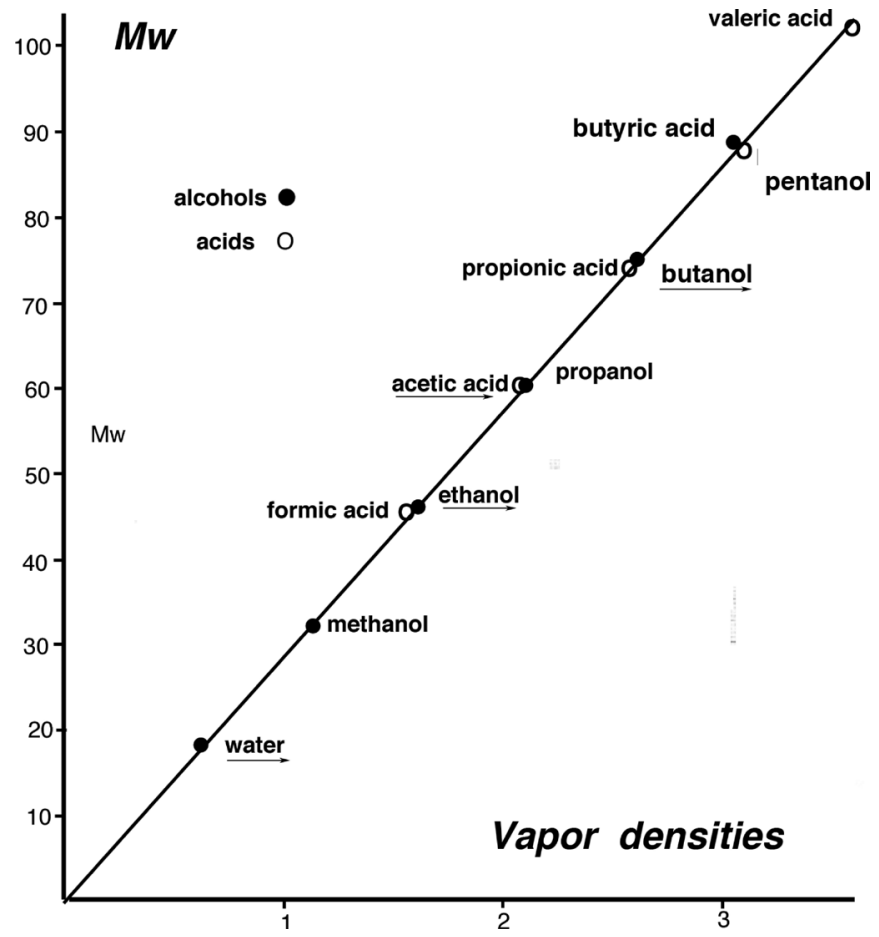

Figure 12. Rf of Fructose with binary solvents and number of carbons of solvents. 
As a first approximation, the $R f$ of the Fructose are plotted on curves as a function of the number of carbon atoms present in the constituents of the formulation of developing solutions according to Table 13 corresponding curves in Figure 13.

Table 13. $R f$ of Fructose and number of carbons.

\begin{tabular}{|c|c|c|c|c|c|c|c|c|c|c|c|c|}
\hline \multirow{2}{*}{ Solvents } & \multicolumn{2}{|c|}{ Water } & \multicolumn{2}{|c|}{ Methanol } & \multicolumn{2}{|c|}{ Ethanol } & \multicolumn{2}{|c|}{ Propanol } & \multicolumn{2}{|c|}{ Butanol } & \multicolumn{2}{|c|}{ Pentanol } \\
\hline & $C$ & $R f$ & $C$ & $R f$ & $C$ & $R f$ & $C$ & $R f$ & $C$ & $R f$ & $C$ & $R f$ \\
\hline Water & 0 & 0.98 & 1 & 0.60 & 2 & 0.49 & 3 & 0.38 & \multicolumn{2}{|c|}{ Demixing } & \multicolumn{2}{|c|}{ Demixing } \\
\hline Formic acid & 1 & 0.93 & 2 & 0.58 & 3 & 0.45 & 4 & 0.58 & 5 & 0.85 & 6 & 0.81 \\
\hline Acetic acid & 2 & 0.86 & 3 & 0.54 & 4 & 0.36 & 5 & 0.25 & 6 & 0.32 & 7 & 0.38 \\
\hline Propionic acid & 3 & 0.86 & 4 & 0.48 & 5 & 0.25 & 6 & 0.00 & 7 & 0.00 & 8 & 0.00 \\
\hline Butyric acid & 4 & 0.93 & 5 & 0.55 & 6 & 0.33 & 7 & 0.00 & 8 & 0.00 & 9 & 0.00 \\
\hline
\end{tabular}

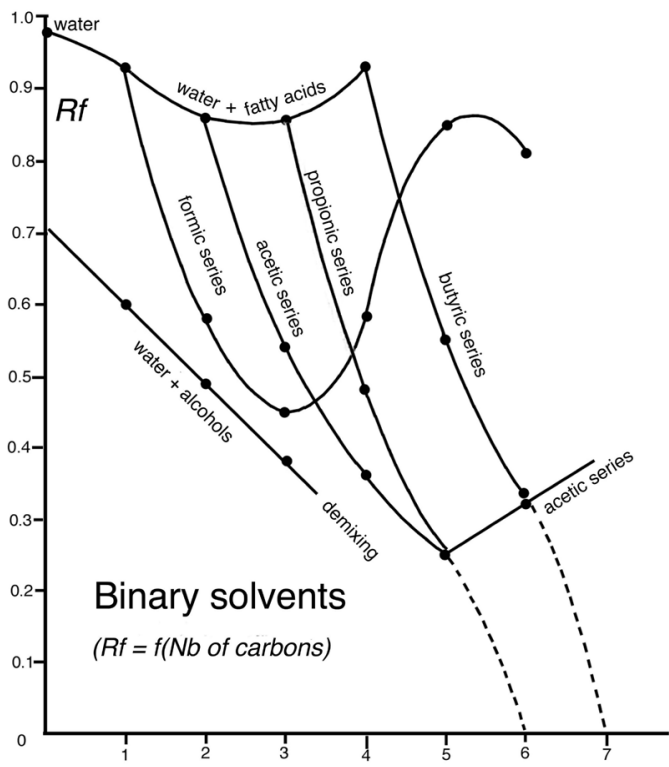

Figure 13. Vapor densities of some organic solvents mixtures.

All these curves (Figure 13) make it possible to visualize the coherence of the proposed chromatographic system. The water/alcohol series gives a straight line revealing the exact proportionality with the number of carbons. With azeotropic mixtures of organic solvents, there is a reduction in the $R f$ of Fructose as a function of the "load" in carbon atoms as has been observed with mineral salts. But with the formic and the acetic series, a rise in $R f$ is observed, due to the relative increase of the total hydrophilic fraction of the mixture of organic solvents, showing the preponderance of the total solvent fraction which produces the same $R f$ whatever the origin of the hydroxyl functions. These numerical data make it possible to calculate the total percentage of the hydroxyls of the constituents of the mixture taking into account the number of active hydroxyls of the organic acids, according to equation (13):

$$
\sqrt[3]{N_{1}\left(\% n_{1} \mathrm{OH}\right)+N_{2}\left(\% n_{2} \mathrm{OH}\right)}=(-\mathrm{OH}) \text { total }
$$


The following curve (Figure 14 and Table 14) shows proportionality between the $R f$ of Fructose and all the hydroxyl fractions. The differences observed are likely to be due to intra-molecular interaction of the miscible liquids.

Table 14. Molar fraction of hydroxyl of binary solvents and $R f$ of Fructose and $R f$ of Fructose.

\begin{tabular}{|c|c|c|c|c|c|c|c|c|c|c|c|c|}
\hline \multirow[b]{2}{*}{ water/alcohol \% } & \multicolumn{2}{|c|}{ water } & \multicolumn{2}{|c|}{ methanol } & \multicolumn{2}{|c|}{ ethanol } & \multicolumn{2}{|c|}{ propanol } & \multicolumn{2}{|c|}{ butanol } & \multicolumn{2}{|c|}{ pentanol } \\
\hline & \multicolumn{2}{|c|}{100} & 9.2 & 90.8 & 13.4 & 86.6 & 26.4 & 73.6 & 49.4 & 50.6 & 55.7 & 44.3 \\
\hline$\% \mathrm{~N}(\mathrm{OH})$ & \multicolumn{2}{|c|}{94.4} & \multicolumn{2}{|c|}{56.8} & \multicolumn{2}{|c|}{44.6} & \multicolumn{2}{|c|}{45.4} & \multicolumn{2}{|c|}{58.2} & \multicolumn{2}{|c|}{61.0} \\
\hline$R f$ of Fructose & \multicolumn{2}{|c|}{0.98} & \multicolumn{2}{|c|}{0.60} & \multicolumn{2}{|c|}{0.49} & \multicolumn{2}{|c|}{0.38} & \multicolumn{2}{|c|}{ demixing } & \multicolumn{2}{|c|}{ demixing } \\
\hline & 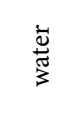 & $\underset{\widetilde{d}}{\mathscr{Z}}$ & 祕 & : & 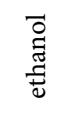 & :己 & 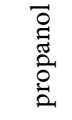 & :己 & 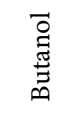 & :己 & 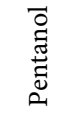 & $\overbrace{\tilde{J}}^{\infty}$ \\
\hline formic ac. $\%$ & 19.0 & 81.0 & 69.9 & 30.1 & 60.2 & 39.8 & 39.6 & 60.4 & 19.4 & 80.6 & 15.8 & 84.2 \\
\hline$\% \mathrm{~N}(\mathrm{OH})$ & \multicolumn{2}{|c|}{47.9} & \multicolumn{2}{|c|}{48.2} & \multicolumn{2}{|c|}{37.0} & \multicolumn{2}{|c|}{33.4} & \multicolumn{2}{|c|}{34.2} & \multicolumn{2}{|c|}{34.0} \\
\hline (2) & \multicolumn{2}{|c|}{77.9} & \multicolumn{2}{|c|}{59.3} & \multicolumn{2}{|c|}{51.7} & \multicolumn{2}{|c|}{55.8} & \multicolumn{2}{|c|}{55.8} & \multicolumn{2}{|c|}{65.4} \\
\hline$R f$ of Fructose & & & & & & & & & & & & \\
\hline acetic ac. $\%$ & 25.4 & 74.60 & 77.0 & 23.0 & 68.6 & 31.4 & 48.7 & 51.3 & 25.8 & 74.2 & 21.3 & 78.7 \\
\hline$\% \mathrm{~N}(\mathrm{OH})$ & & & & & & & & & & & & \\
\hline (2) & & & & & & & & & & & & \\
\hline$R f$ of Fructose & & & & & & & & & & & & \\
\hline propionic ac. $\%$ & 59.1 & 40.9 & 93.5 & 6.5 & 90.3 & 9.7 & 80.2 & 19.8 & 59.7 & 40.3 & 58.5 & 41.5 \\
\hline$\% \mathrm{~N}(\mathrm{OH})$ & & & & & & & & & & & & \\
\hline (2) & & & & & & & & & & & & \\
\hline$R f$ of Fructose & & & & & & & & & & & & \\
\hline Butyric ac. \% & 82.5 & 17.5 & 97.9 & 2.1 & 96.8 & 3.2 & 92.9 & 7.1 & 92.8 & 7.20 & 78.9 & 21.1 \\
\hline$\% \mathrm{~N}(\mathrm{OH})$ & & & & & & & & & & & & \\
\hline (2) & & & & & & & & & & & & \\
\hline$R f$ of Fructose & & & & & & & & & & & & \\
\hline
\end{tabular}

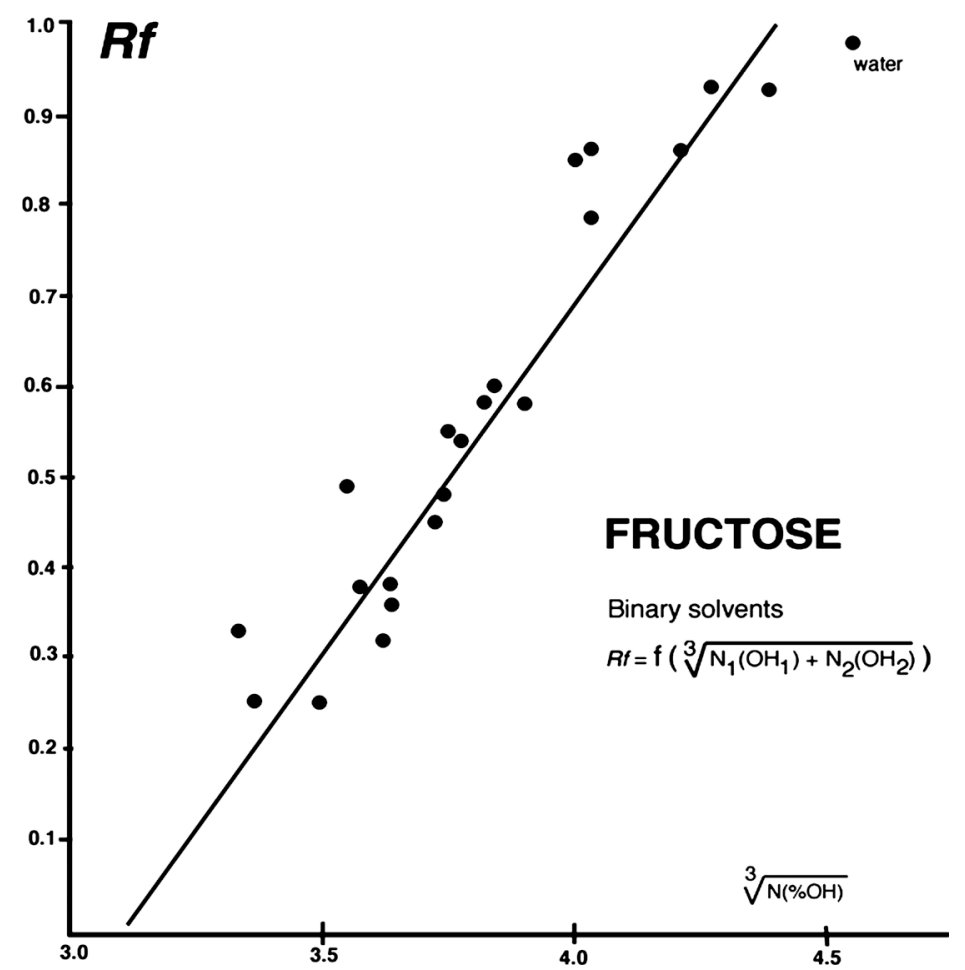

Figure 14. Fructose and binary solvents. 


\section{Discussion}

\subsection{Aqueous Solutions of Electrolytes}

The values obtained by means of potassium and sodium halides reveal a fairly good accuracy of chromatography on paper and the validity of the analytical method used. However, some anomalies have been observed and explained by the universality of the adsorption/desorption phenomenon, the added salts are also adsorbed by the cellulose of the paper, from where a flight of the $R f$ towards the front of the solvent for the very low dilutions of the salts eluent solutions. Similarly, for very concentrated solutions, there is an early departure of the $R f$ before the equilibrium point $R f_{x}^{0}$, due to the adsorption of the salts during the course of the eluent before reaching the substance under test at the analysis, 3 $\mathrm{cm}$ from the base, creating a forehead of a few millimeters of water "purified" of its salts. The use of silica column chromatography will eliminate these anomalies by the prior passage of the eluent solution in the column prior to analyze.

\subsubsection{Alkali Halides}

Anhydrous potassium halides are more easily interpretable (see Table 1) than sodium halides which have a hydrated form (see Table 2). Potassium fluoride has not been tested. Each control dye showed a $R f_{x}^{0}$ corresponding to the equilibrium point between the adsorbent capacity of the solid support and the eluting power of the developing liquid and a common $C_{x}^{0}$ for the same homogeneous series, as well as a characteristic constant for each dye according to Equation (5). Bromide and sodium iodide have a di-hydrated form in the dry state, this study has shown that this hydrated form persists in solution and that in the case of iodide, the capture of four molecules of solvation water, helps to increase the concentration of this salt in the remaining free water where the chromatographic phenomenon occurs. Table 3 and Table 4 show highlight these differences in behavior.

The ratio between the molecular weights and the quotient $R f_{x}^{0} / C_{x}^{0}$ makes it possible to obtain new numerical data making it possible to determine the potential of a carboxylic function with respect to two other sulfonyl functions in the case of Tartrazine. On the other hand, the graphical representation of the ratio $R f_{x}^{0} / C_{x}^{0}$ as a function of the molecular weight of the salts is distributed according to their polarity as on cathode and virtual anode.

The study of the sodium halide curves of the different dyes reveals a difference of 0.09 in terms of Rf between the anhydrous and hydrated forms corresponding to $2 \mathrm{H}_{2} \mathrm{O}$. This observation made it possible to determine an $R f$ greater than 1.00 for the Orange G, which shows the limit of the chromatography on paper.

An experimental limit of the chromatographic phenomenon has been evaluated at $260 \mathrm{in}$ terms of molecular weight. This limit appears to be common to all alkaline earth halides ( $M W$ of cesium iodide CsI $=259.81$ ). This limit can only be explained after having determined other similar, but different value limits, by means of other homologous series of halides of the Mendeleev periodic table, which might lead to the establishment of new properties. 


\subsubsection{Carboxylic Salts (Aliphatic Salts)}

A homologous series of sodium carboxylic (fatty acids), confirmed the results obtained by means of homologous series of mineral salts, subject to the inversion of the order of the curves which would seem due to the influence of the organic radical of these salts as will show the part of this study devoted to organic solvents. It has been possible to determine the density of sodium propionate hygroscopic and amorphous from the molecular volumes of sodium format and acetate. It appears proportionality between the lengths of the carbon chain added of the salifying atom. The existence of a sodium propionate monohydrated has been demonstrated.

\subsubsection{Phosphates of Monovalent Salts}

The chromatograms of the phosphates confirm those obtained previously. Anhydrous potassium phosphates behave like anhydrous potassium halides. Sodium tri-phosphate gives seemingly unusable results but explains the phenomenon of mercerizing by the modification of the cellulose of the paper under the action of the soda liberated by this very alkaline salt. It was possible to calculate the molecular volume of di potassium phosphate hence his density. The study of the ratio between the molecular weight $M w$ and the slope $R f_{x}^{0} / C_{x}^{0}$ reveals a new family of the graphical representation developing only in the positive zone of the graph. The slopes of the lines of potassium and sodium phosphates meet at point 95 , corresponding to the molecular weight of the anion $\mathrm{PO}_{4}^{3-}=94.97$ while the straight lines joining the potassium and sodium phosphates meet on the left ordinate of the $R f$.

The Orange $G$ behaves differently from other dyes by inverting the lines leading to the point of occurrence 95 relative to the other three dyes. During this study, we observed this difference in behavior between the $G$ and $S$ Oranges, which their very similar chemical structures did not seem to justify. The regularity of our determinations has led us to hypothesize that, in aqueous solution, the Orange G, by the proximity of its two sulphonyl functions, retained only one atom of sodium.

With the other three dyes, it's the mono and di hydrate salts which join at point 95 of the abscissa axis, whereas the straight lines of sodium and potassium phosphates meet in the ordinate of left, at the exception of Amaranth, whose $R f$ are very weak, which increases the relative error due to the method, hence the indeterminacy of his meeting point.

The molecular volume of hygroscopic potassium phosphate and its density were calculated to establish its representative straight line compared to that of sodium phosphates. All these curves confirm the previous results, with the exception of highly alkaline tri sodium phosphate, which modifies the properties of paper cellulose.

\subsection{Organic Solvents}

The $R f$ of Fructose chromatographed with pure organic solvents are proportional to their hydroxyl content. This property makes it possible to assimilate these solvents to perfect theoretical solutions without the interactions between the hy- 
drophilic moieties $(-\mathrm{OH})$ and the lipophilic moiety $\left(-\mathrm{CH}_{2}\right)$ of type 1-1, 2-2 and 1-2. This explains the perfect relationship between the $R f$ obtained with pure organic solvents or in mixture with water and the cubic root of total hydroxyl fraction (Equation (14)).

In the case of mixtures of volatile organic solvents, it necessary to calculate the composition of the eluent solvents according to the same composition as theirs vapors saturating the chromatographic chamber, in order to avoid variations in the composition of the mixture during the elution. The determining of the total percentage of the hydroxyls showed a relative proportionality between the sum of the hydroxyls and the $R f$ of the Fructose. Deviations appear to be due to intramolecular interactions between the mixed solvents.

\section{Conclusions}

We have demonstrated the regular progression of $R f$ as a function of the concentration of sodium and potassium halides in aqueous solution expressed in molecular volume, making it possible to exploit the mathematical functions of the right triangle. This allowed us to derive an $R f_{x}^{0}$ at the origin of the development of $R f$ which is the point of equilibrium between the adsorptive power of the solid phase and the eluting power of the liquid phase. We also found the persistence of the hydrated form in solution for bromide and sodium iodide, as well as the capture of four molecules solvation water by sodium iodide. On the other hand, the graphical representation of the ratios between the quotients $R f_{x}^{0} / C_{x}^{0}$ as a function of the molecular weights is distributed according to their polarity as on cathode and virtual anode. An experimental limit of the chromatographic phenomenon has been evaluated at 260 in terms of molecular weight; this limit seems to be common to all alkaline earth halides. This limit was to be different for other homogeneous salts of metal halides belonging to other groups of the Mendeleev classification, which would make it possible to establish new properties. Further, this method made it possible to determine some other physical properties that could not to be obtained directly.

The use of Fructose as a control of variations of pure organic solvents or azeotropic mixtures with water showed a perfect proportionality between the $R f$ and the total percentage of hydroxyl functions present. With organic solvents in azeotropic binary mixture, the proportionality is less apparent, likely to result from intra molecular interactions.

We strongly hope that these results will be confirmed by the scientific community by means of volumetric silica column chromatography, which is not limited and avoids the drawbacks encountered during this study, by the prior passage of the eluent in the column and that it is completed by means of lithium, rubidium and cesium halides. If the results obtained were consistent with those described in this article, it would be interesting to confirm them in gas chromatography. In the latter case, the eluent gases of the series of rare gases no longer have a static but dynamic role justifying the return to mass of these gases and the speed will be their flow rate 
reported at the gaseous molecular volume of 22.412 liters (Equation 14).

If all these results were in agreement, it would be possible to apply it to the distillation, which can be defined as a succession of gas chromatographies, the other constituents of the mixture to be distilled acting as the added salts in aqueous chromatography and thus to unify the separation techniques.

$$
\left.\left[\frac{N_{1}}{N_{1} M w_{1}+1 / 2\left[M w_{\text {gas }}\left(\frac{22.412}{\text { time }}\right)^{2}\right]}\right]\right]_{T p}
$$

All these approaches are summarized in Figure 15 from a mathematical point of view.

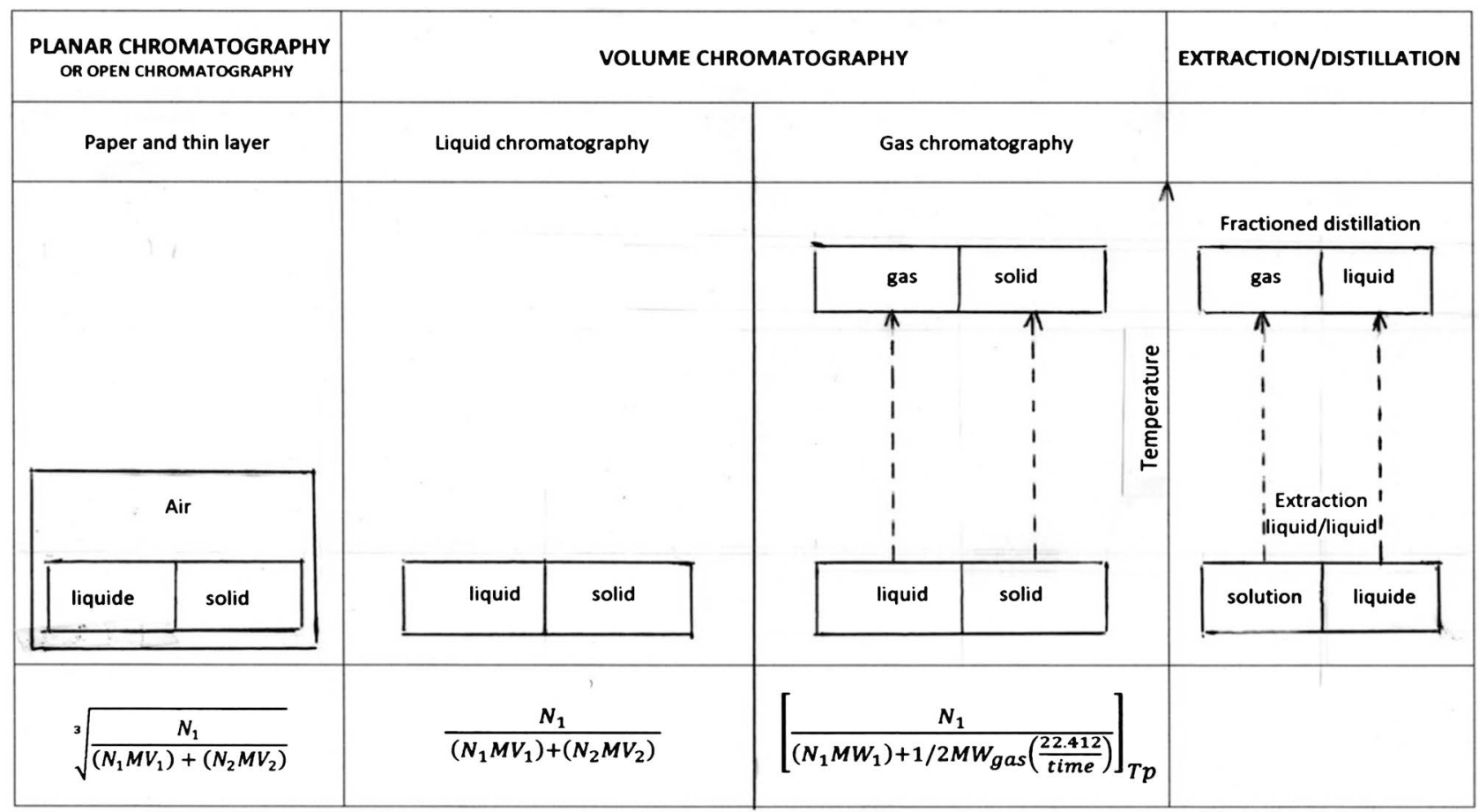

Figure 15. Filiation of separative techniques.

\section{Acknowledgements}

We thank with great gratitude to Professor Thierry Prangé, who was kind enough to take interest in our work, to correct it and advise us in his presentation.

\section{Conflicts of Interest}

The author declares no conflicts of interest regarding the publication of this paper.

\section{References}

[1] Tswett, M.S. (1906) Physikalisch-chemische Studie zur Chlorophylladsorption. 
Berichte der Deutschen botanisch Gesellschaft, 24, 316-323.

[2] Langmuir, I. (1918) The Adsorption of Gas on Plane Surface of Glass, Mica and Platinum. J. of American Chemical Society, 40/9, 1361-1403.

https://doi.org/10.1021/ja02242a004

[3] Kuhn, R. and Lederer, E. (1931) Fraktionierung und isomerisierung des carotene. Die Naturwissenschaften, 19, 306. https://doi.org/10.1007/BF01520417

[4] Consden, R., Gordon, A.H. and Martin, A.J.P. (1944) Qualitative Analysis of Proteins: A Partition Chromatographic Method Using Paper. Biochemical Journal, 38, 224-232. https://doi.org/10.1042/bj0380224

[5] Block, R.J., Durrum, E.L. and Zweig, G. (1958) A Manual of Paper Chromatography and Paper Electrophoresis. 2nd Edition, Academic Press Publishers, New York.

[6] Salentijn, G.I., Grajewski, M. and Verpoorte, E. (2018) Reinventing Biochemical Analysis with Paper. Analytical Chemistry, 90, 13815-13825.

https://doi.org/10.1021/acs.analchem.8b04825

[7] Hackman, R.H. and Lazarus, M. (1955) Paper Chromatography of Amino Acids Containing Glutamic or Aspartic Acid. Biochimica et Biophysica Acta, 17, 147-148. https://doi.org/10.1016/0006-3002(55)90335-8

[8] Mizell, M. and Simpson Jr., S.B. (1951) Paper Chromatographic Separation of Amino-Acids: A Solvent to Replace Phenol. Journal of Chromatography A, 5, 157-160. https://doi.org/10.1016/S0021-9673(01)92835-3

[9] Martin, A.J.P. and Synge, R.L.M. (1941) A New Form of Chromatogram Employing Two Liquid Phases. Biochem. J., 35, 1358.

[10] Boggs, I., Consden, I.S., Ehrenthal, I., Koch, R. and Smisth, F. (1950) Separation and Identification of Sugar Using Paper Chromatography. Nature, 166, 520-523. https://doi.org/10.1038/166520b0

[11] Viejo, J.P. (1956) Identification des drogues et contrôle des médicaments d'origine végétale par chromatographie sur papier. Thesis Faculty of Pharmacy, Paris, 22-28. 